\title{
Selective deficiencies in descending inhibitory modulation in neuropathic rats: implications for enhancing noradrenergic tone
}

\author{
Ryan Patel ${ }^{a, \star}$, Chaoling Qu ${ }^{b}$, Jennifer Y. Xie ${ }^{b}$, Frank Porreca ${ }^{b}$, Anthony H. Dickenson ${ }^{a}$
}

\begin{abstract}
Pontine noradrenergic neurones form part of a descending inhibitory system that influences spinal nociceptive processing. Weak or absent descending inhibition is a common feature of chronic pain patients. We examined the extent to which the descending noradrenergic system is tonically active, how control of spinal neuronal excitability is integrated into thalamic relays within sensorydiscriminative projection pathways, and how this inhibitory control is altered after nerve injury. In vivo electrophysiology was performed in anaesthetised spinal nerve-ligated (SNL) and sham-operated rats to record from wide dynamic range neurones in the ventral posterolateral thalamus (VPL). In sham rats, spinal block of $\alpha_{2}$-adrenoceptors with atipamezole resulted in enhanced stimulus-evoked and spontaneous firing in the VPL, and produced conditioned place avoidance. However, in SNL rats, these conditioned avoidance behaviours were absent. Furthermore, inhibitory control of evoked neuronal responses was lost, but spinal atipamezole markedly increased spontaneous firing. Augmenting spinal noradrenergic tone in neuropathic rats with reboxetine, a selective noradrenergic reuptake inhibitor, modestly reinstated inhibitory control of evoked responses in the VPL but had no effect on spontaneous firing. By contrast, clonidine, an $\alpha_{2}$ agonist, inhibited both evoked and spontaneous firing, and exhibited increased potency in SNL rats compared with sham controls. These data suggest descending noradrenergic inhibitory pathways are tonically active in sham rats. Moreover, in neuropathic states, descending inhibitory control is diminished, but not completely absent, and distinguishes between spontaneous and evoked neuronal activity. These observations may have implications for how analgesics targeting the noradrenergic system provide relief.
\end{abstract}

Keywords: In vivo electrophysiology, Ventral posterolateral thalamus, Conditioned place avoidance, Spinal nerve ligation, Neuropathic pain, Descending inhibition, Noradrenaline, Noradrenaline reuptake inhibitor, $\alpha 2$-adrenoceptor

\section{Introduction}

Monoamine reuptake inhibitors are one of the commonly prescribed treatments for neuropathic pain, yet across different etiologies number needed to treat values only average around 6.4. ${ }^{17}$ Chronic pain conditions are frequently associated with a loss of endogenous inhibition, ${ }^{68}$ and clearly, enhancement of noradrenergic tone can be an effective treatment. ${ }^{17,79}$ Importantly, dividing patients into strata based on symptoms, which may reflect distinct underlying pathophysiological mechanisms, could improve patient outcomes. ${ }^{13,60,79}$

\footnotetext{
Sponsorships or competing interests that may be relevant to content are disclosed at the end of this article.

a Department of Neuroscience, Physiology \& Pharmacology, University College London, London, United Kingdom, ${ }^{b}$ Department of Pharmacology, University of Arizona, Tucson, AZ, United States

${ }^{*}$ Corresponding author. Address: University College London, London WC1E 6BT, United Kingdom. Tel.: +442076793737; fax: +442076797298. E-mail address: ryan.patel.10@ucl.ac.uk (R.Patel).

Supplemental digital content is available for this article. Direct URL citations appear in the printed text and are provided in the HTML and PDF versions of this article on the journal's Web site (www.painjournalonline.com).

PAIN 00 (2018) 1-13

Copyright $\odot 2018$ The Author(s). Published by Wolters Kluwer Health, Inc. on behalf of the International Association for the Study of Pain. This is an open access article distributed under the Creative Commons Attribution License 4.0 (CCBY), which permits unrestricted use, distribution, and reproduction in any medium, provided the original work is properly cited.

http://dx.doi.org/10.1097/j.pain.0000000000001300
}

The importance of descending noradrenergic systems in pain chronicity is highlighted by the development of conditioned pain modulation (CPM) as a diagnostic tool as part of quantitative sensory testing. Conditioned pain modulation, a paradigm whereby heterotopic noxious stimulation reduces the pain percept of a test stimulus, provides a readout of the integrity of net endogenous inhibitory mechanisms. Patients with low CPM have increased propensity to develop chronic pain after surgery, ${ }^{78}$ and neuropathic patients with low CPM are more likely to respond to treatment with duloxetine (a serotonin and noradrenaline reuptake inhibitor [SNRI]) or tapentadol (a dual $\mu$-opioid receptor agonist and noradrenaline reuptake inhibitor). ${ }^{44,79}$ These clinical observations have been successfully back-translated; diffuse noxious inhibitory controls, the analogous process to CPM in animals, are mediated by noradrenaline and are globally absent in neuropathic rats yet can be restored by tapentadol and reboxetine (an NRI), ${ }^{3}$ and the ability to engage descending inhibitory pathways influences severity of pain after nerve injury in rats. ${ }^{12,75}$ Inhibition of spinal $\alpha_{2}$-adrenoceptors also unmasks hypersensitivity in animals with no symptoms after nerve ligation and contralateral hypersensitivity. ${ }^{12,28,75}$ These studies suggest that noradrenergic pathways can act temporally and spatially to restrict spinal hypersensitivity and support a loss of inhibitory drive in neuropathic pain states.

Studies of descending modulation of pain typically use spinal endpoints, either reflexive or electrophysiological. The former assay is limited to examining withdrawal thresholds. The latter affords the ability to examine modulation of suprathreshold input, but the projection pathways of these neurones are rarely 
confirmed. Little is known about the impact of descending brainstem control of spinal excitability on neuronal activity in higher centres. To this end, we have studied the modulation of ascending spinal activity and subsequent integration into the ventral posterolateral thalamus (VPL), a key sensory discriminative relay. During neurosurgical procedures, microstimulation of the ventralis caudalis can evoke thermal and mechanical sensations. ${ }^{37,46}$ Furthermore, polymodal neurones within this lateral thalamic pathway have the capacity to encode stimulus intensity and have been characterised across species, including humans. ${ }^{1,33,80}$ Unlike spinal neuronal responses after peripheral nerve injury in rats,, ,48,51 VPL wide dynamic range (WDR) neurones exhibit higher rates of spontaneous firing and exaggerated responses to evoked stimulation. ${ }^{21,50,69}$ These electrophysiological recordings allow for a linear correlation of stimulus intensity and response, and can provide a sensory neuronal correlate of evoked hypersensitivity after injury. ${ }^{45}$ In an attempt to define drug effects on affective state, we additionally perform conditioned place avoidance (CPA) testing as this assay has the advantage of providing insight into the rewarding or aversive nature of pharmacological interventions.

\section{Methods}

\subsection{Animals}

Naïve, sham-operated, and spinal nerve-ligated (SNL) (14-20 days after surgery) male Sprague-Dawley rats (250-350 g) were used for behavioural and electrophysiological experiments (Harlan, Indianapolis, IN and Biological Services, University College London, United Kingdom, respectively). Animals were group-housed (maximum of 4) on a conventional 12 hours:12 hours light-dark cycle; food and water were available ad libitum. Temperature and humidity of holding rooms were closely regulated. Electrophysiological and surgical procedures described here were approved by the UK Home Office and adhered to the Animals (Scientific Procedures) Act 1986. Behavioural and surgical procedures were approved by the Institutional Animal Care and Use Committee of the University of Arizona. All experiments were designed in accordance with International Association for the Study of Pain ethics guidelines. ${ }^{82}$

\subsection{Spinal nerve ligation surgery}

Spinal nerve ligation surgery was performed as previously described. ${ }^{26}$ Rats (130-140 g) were maintained under $2 \%$ vol/ vol isoflurane anaesthesia delivered in a 3:2 ratio of nitrous oxide and oxygen. Under aseptic conditions, a paraspinal incision was made and the tail muscle excised. Part of the L5 transverse process was removed to expose the left L5 and L6 spinal nerves, which were then isolated with a glass nerve hook (Ski-Ry, London, United Kingdom), and ligated with a nonabsorbable 60 braided silk thread proximal to the formation of the sciatic nerve. The surrounding skin and muscle was closed with absorbable 40 sutures. Sham surgery was performed in an identical manner omitting the nerve hook/ligation step. All rats groomed normally and gained weight in the following days after surgery.

\subsection{Intrathecal cannulation}

For behavioural studies, intrathecal catheters were implanted 5 to 7 days before sham or spinal nerve ligation surgery as described before. ${ }^{73,77}$ Rats were anaesthetised with intraperitoneal ketamine $(80 \mathrm{mg} / \mathrm{kg}) / x y l a z i n e ~(12 \mathrm{mg} / \mathrm{kg})$. After aseptic preparation, the atlanto-occipital membrane was exposed and incised. A 7.5- cm long PE-10 catheter was slowly inserted into the intrathecal space through the membrane to the lumbar spinal cord. The catheter was secured inside the muscle, and the skin was closed with wound clips. The animals were single-housed after recovery. Animals exhibiting signs of paralysis $(<5 \%)$ were removed from the study.

\subsection{Paw withdrawal thresholds}

Baseline thresholds were determined 1 day before sham or spinal nerve ligation surgery. Rats were placed in isolation inside chambers on a wire mesh floor and allowed to acclimatise. The withdrawal threshold of the hind paw was measured in response to probing of the plantar surface with a series of calibrated von Frey filaments (Stoelting, Wood Dale, IL) in logarithmically spaced increments ranging from 0.41 to $15 \mathrm{~g}$. Each filament was applied perpendicularly to the plantar surface of the left hind paw for 3 seconds; flinching, licking, shaking, or other directed behaviours were considered positive responses. Withdrawal threshold was determined by sequentially increasing or decreasing the stimulus force (starting with the 2-g filament) using the "up-down" method as previously described. ${ }^{8}$ Pharmacology was performed on postoperative day 17; withdrawal thresholds were determined before dosing and subsequently at 20,40, and 60 minutes after dosing. The experimenter was blinded to treatment group; rats were randomised into groups (by an independent person), and received either intrathecal vehicle $(5-\mu \mathrm{L}$ normal saline) or atipamezole (20 $\mu \mathrm{g} / 5 \mu \mathrm{L})$.

\subsection{Conditioned place avoidance}

A single-trial CPA protocol was performed as previously described. $^{32}$ On preconditioning day (day 13 after spinal nerve ligation/sham surgery), rats were placed into the CPA boxes with access to all chambers, and time spent in each chamber over 15 minutes was determined by an automated process. To assure no chamber preference bias before conditioning, animals spending more than $80 \%$ (720 seconds) or less than 20\% (180 seconds) of the total time in a chamber were eliminated from further testing. Chamber pairings were counterbalanced between the control and drug chambers. The following day, all rats received $5-\mu \mathrm{L}$ vehicle (normal saline) intrathecally and were immediately placed into one randomly assigned conditioning chamber for 30 minutes without access to the other chamber. Four hours later in the afternoon, rats received intrathecal atipamezole $(20 \mu \mathrm{g} / 5 \mu \mathrm{L})$ paired with the opposite chamber for 30 minutes. On test day (day 15 after spinal nerve ligation/sham surgery), 20 hours after the afternoon pairing, rats were placed in the apparatus with access to all chambers again, and their behaviour was recorded for 15 minutes for automated analysis of chamber preference/ avoidance. The difference score was calculated by subtracting the baseline time from the test time. The order of pairing with morning saline and afternoon atipamezole avoided possible effects of extended duration of action of the drug with learning and is consistent with our previous methods. ${ }^{32}$

\subsection{In vivo electrophysiology}

Thalamic neuronal recordings were performed as previously described. ${ }^{50}$ The experimenter was not blind to the injury or drug administration. Animals were initially anaesthetised with $3.5 \%$ vol/ vol isoflurane delivered in 3:2 ratio of nitrous oxide and oxygen. Once areflexic, a tracheotomy was performed and rats were subsequently maintained on $1.5 \% \mathrm{vol} / \mathrm{vol}$ isoflurane for the 
remainder of the experiment. Rats were secured in a stereotaxic frame, and after exposure of the skull, coordinates for the right ventral posterolateral (VPL) thalamus (contralateral to injury) were calculated in relation to bregma $(2.28-\mathrm{mm}$ caudal and $3.2-\mathrm{mm}$ lateral). ${ }^{70} \mathrm{~A}$ small craniotomy was performed with a high-speed surgical microdrill. The muscle overlying the lumbar vertebrae was removed, a partial laminectomy was performed to expose the L4 to L6 lumbar region, and the overlying dura was removed. Once haemostasis was achieved, the surrounding muscle was coated in petroleum jelly to form a hydrophobic barrier to contain the drug. Extracellular recordings were made from VPL thalamic neurones with receptive fields on the glabrous skin of the left paw hind toes (see Fig. 1 for stereotaxically determined recording sites) using 127- $\mu \mathrm{m}$ diameter 2-M $\Omega$ parylene-coated tungsten electrodes (A-M Systems, Sequim, WA). The receptive field was stimulated using a range of natural stimuli (brush, von Frey filaments-2, 8, 15, 26, and $60 \mathrm{~g}$ and heat-35, 42, 45, and $48^{\circ} \mathrm{C}$ ) applied over a period of 10 seconds per stimulus. The heat stimulus was applied with a constant water jet onto the centre of the receptive field. Acetone and ethyl chloride $(100 \mu \mathrm{L})$ were applied as an evaporative innocuous cooling and noxious cooling stimulus, respectively, ${ }^{34}$ and responses quantified over 10 seconds after application. Evoked responses to room temperature water $\left(25^{\circ} \mathrm{C}\right)$ were minimal, or frequently completely absent, and subtracted from acetone-evoked and ethyl chloride-evoked responses to control for any concomitant mechanical stimulation during application. Stimuli were applied starting with the lowest intensity stimulus with approximately 40 seconds between stimuli in the following order: brush, von Frey, cold, and heat.

Animals were under anaesthesia for 4 to 6 hours. This included obtaining baseline responses over the course of an hour and determining drug effects over 2 hours. Baseline recordings were stable over the first hour of recording; however, subsequent timedependent or order-dependent effects of drug dosing cannot be ruled out over the remainder of the experiment. Baseline recordings were made with $25-\mu \mathrm{L}$ vehicle applied topically to the dorsal aspect of the spinal cord (after aspiration of any cerebrospinal fluid), hence all observed effects can be attributed to drug actions. After 3 baseline trials (stimuli applied in the order described above with 5 minutes between each set of trials, data were averaged to give control values), the vehicle was removed, and $50-\mu \mathrm{g}$ and $100-\mu \mathrm{g}$ atipamezole (Sigma, Gillingham, United Kingdom), or $10-\mu \mathrm{g}$ and $50-\mu \mathrm{g}$ reboxetine mesylate (Tocris, Abingdon, United Kingdom) were cumulatively applied to the spinal cord in a volume of $25 \mu \mathrm{L}$ (vehicle: $97 \%$ normal saline, 2\% cremophor, 1\% dimethylsulfoxide), and neuronal responses were characterised 20 and 40 minutes after dosing. For clonidine studies, 50- and 100- $\mu$ g clonidine hydrochloride (Sigma) were applied to the cord in a volume of $25 \mu \mathrm{L}$ (vehicle: normal saline), and neuronal responses were characterised 10 and 30 minutes after dosing; time point of peak change from baseline is plotted. The second dose was applied approximately 50 to 60 minutes after aspiration of the first dose; excess drug was washed from the cord with $25-\mu \mathrm{L}$ vehicle (applied for 2-3 minutes). Drug doses were guided by previous studies, ${ }^{3,7,27,54,64}$ and their effects were tested in a pilot study.

Data were captured and analysed by a CED1401 interface coupled to a computer with Spike2 v6 software (Cambridge Electronic Design, Cambridge, United Kingdom) with rate functions. The signal was amplified (×6000), bandpass filtered (low-/highfrequency cutoff $1.5 / 2 \mathrm{kHz}$ ), and digitised at rate of $20 \mathrm{kHz}$. Spike sorting was performed post hoc with Spike2 using fast Fourier transform followed by 3-dimensional principal component analysis of waveform feature measurements for multiunit discrimination. Neurones were recorded from one site per rat; 1 to 3 neurones were characterised at each site. Stimulus-evoked neuronal responses were determined by subtracting total spontaneous neuronal activity in the 10-second period immediately preceding stimulation. Spontaneous firing of individual neurones (number of spikes per second) is expressed as the mean of these 10-second periods. Burst firing (number of bursts per second) was determined over a period of 60 seconds in the absence of stimulation as previously described. ${ }^{23}$ Burst parameters were maximum initial interval signifying burst onset (6 ms), longest interspike interval allowed within burst (9 ms), and minimum number of events in a burst (2).

\subsection{Statistics}

Statistical analyses were performed using SPSS v25 (IBM, Armonk, NY). Heat and mechanical coding of neurones were compared with a 2-way repeated-measures (RM) analysis of variance (ANOVA), followed by a Bonferroni post hoc test for paired comparisons. Cold, brush, and spontaneous/burst firing were compared with a 1-way RM ANOVA, followed by a Bonferroni post hoc test for paired comparisons. Conditioned place avoidance measures were compared with a 2-way RM ANOVA, followed by a Bonferroni post hoc test for paired comparisons, whereas difference scores were compared with an unpaired Student $t$ test. Where appropriate, sphericity was tested using Mauchly test; the Greenhouse-Geisser correction was applied if violated. Paw withdrawal time courses were compared with the Friedman test, followed by a Wilcoxon post hoc and
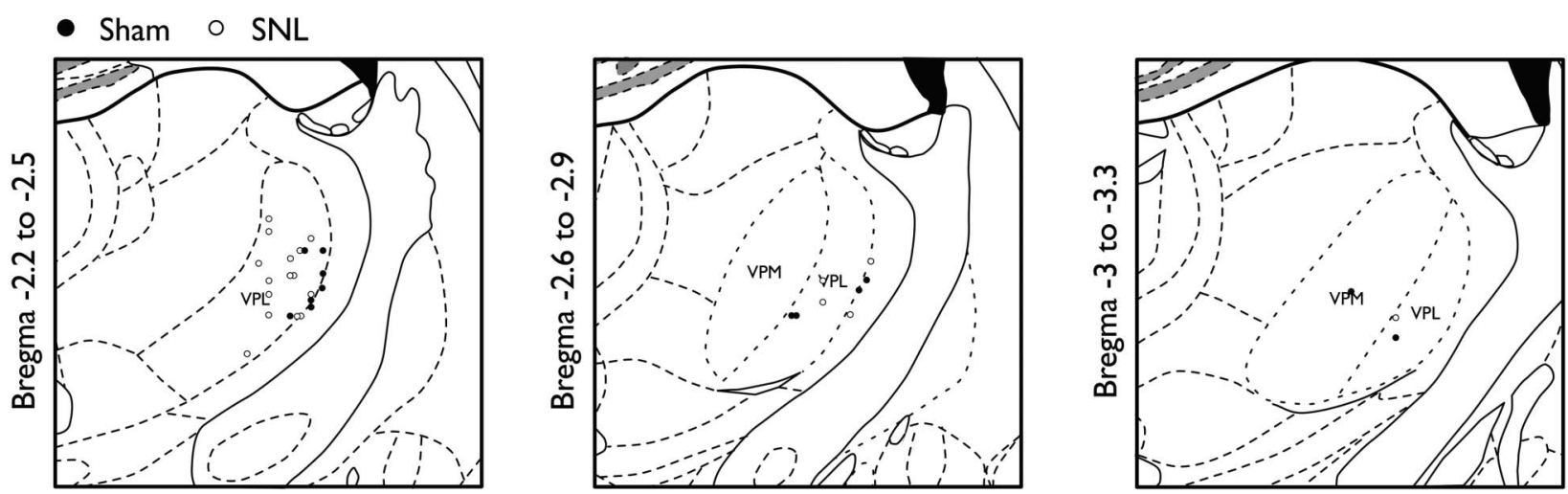

Figure 1. Recording sites within the ventral posterolateral thalamus from 13 sham and 20 neuropathic rats. Filled circles $(\mathbf{O})$ represent sham, and open circles $(O)$ represent spinal nerve-ligated (SNL) rat experiments. 
Bonferroni correction for paired comparisons. Minimum group sizes were determined by a priori calculations ( $\alpha 0.05,1-\beta 0.8)$. All data represent mean $\pm 95 \%$ confidence interval. ${ }^{\star} P<0.05$, ${ }^{\star \star} P<0.01,{ }^{\star \star \star} P<0.001$.

\section{Results}

\subsection{Spinal $\alpha_{2}$-adrenoceptor inhibition has no effect on stimulus-evoked withdrawal responses in sham and spinal nerve-ligated rats}

To determine the extent of any descending inhibitory control of hind paw withdrawal responses, the $\alpha_{2}$-adrenoceptor antagonist atipamezole ( $20 \mu \mathrm{g} / 5 \mu \mathrm{L}$ ) was delivered intrathecally to sham and SNL rats, and withdrawal thresholds to punctate mechanical stimulation quantified. In sham-operated rats, withdrawal thresholds after surgery (day 17) were comparable with baseline responses (Wilcoxon test, $P=1.00$ ), whereas SNL rats exhibited mechanical hypersensitivity after peripheral nerve injury (Wilcoxon test, $P=0.00098$ ) (Fig. 2A). Neither intrathecal vehicle nor atipamezole altered withdrawal thresholds in sham-operated rats (Friedman test, vehicle: $P=1.00$, atipamezole: $P=0.392$ ). Similarly, in SNL rats neither vehicle nor atipamezole had any overall effect on established mechanical hypersensitivity (Friedman test, vehicle: $P=0.478$, atipamezole: $P=0.069$ ) (Fig. 2B).

\subsection{Wide dynamic range neurones in the VPL exhibit hyperexcitability in spinal nerve-ligated rats}

Behavioural observations were extended to include a wider range of modalities and intensities by characterising sensory neuronal processing in the VPL. Wide dynamic range neurones were identified on the basis of responses to brush, noxious punctate mechanical stimulation, and noxious thermal stimulation of the receptive field. After obtaining stable baseline responses, pharmacological studies were performed. A total of 49 neurones were characterised; Table 1 summarises predrug baseline responses to evoked stimulation. Wide dynamic range neurones in SNL rats exhibited greater stimulus-evoked responses, and higher rates of spontaneous and burst firing consistent with our previous observations. ${ }^{50}$ In a separate study, this elevated spontaneous firing rate was inhibited by spinal and intraplantar lidocaine in SNL rats (data not shown) implying ongoing activity in sensory projection pathways, although we cannot conclude whether this represents noxious activity.

\subsection{Spinal $\alpha_{2}$-adrenoceptor inhibition reveals tonic noradrenergic inhibitory tone in naïve/sham rats}

After application of 50- and 100- $\mu$ g atipamezole to the spinal cord, inhibition of $\alpha_{2}$-adrenoceptors increased evoked thalamic neuronal responses to low intensity $(8 \mathrm{~g})$ and to intensities that may reach and then exceed noxious levels $(15,26$, and $60 \mathrm{~g})$ of punctate mechanical stimulation (2-way RM ANOVA $P=0.000096, \mathrm{~F}_{2,20}=$ 15.21) (Fig. 3A). In addition, heat-evoked responses were increased at noxious intensities of stimulation (2-way RM ANOVA $\left.P=0.019, F_{2,20}=4.899\right)$ (Fig. 3B). Acetone and ethyl chloride were applied as innocuous and noxious evaporative cooling stimuli, respectively. Neuronal responses to innocuous cooling were unaffected by spinal atipamezole (1-way RM ANOVA $P=$ 0.144, $\quad F_{1.28,12.79}=2.383$ ); however, noxious cold-evoked responses were facilitated (1-way RM ANOVA $P=0.016, F_{2,20}$ $=5.096)$ (Fig. 3C). Dynamic brush-evoked responses were also enhanced after dosing (1-way RM ANOVA $P=0.007, F_{2,20}=6.49$ ) (Fig. 3D). Spontaneous activity increased in $8 / 11$ units within 5 to
10 minutes of drug application (1-way RM ANOVA $P=0.028$, $F_{1.13,11.30}=6.079$ ) (Fig. 3E), and this increased activity was sustained for the duration of the experiment. However, there was no overall effect on the burst rate (1-way RM ANOVA $P=0.069$, $\left.F_{1.14,11.37}=3.926\right)($ Fig. 3F). Effect sizes in naïve $(n=4$ neurones from 3 rats) and sham animals ( $n=7$ neurones 5 rats) were comparable and thus were pooled for analysis.

\subsection{Spinal $\alpha_{2}$-adrenoceptor inhibition reveals a selective loss of descending inhibitory control of evoked neuronal responses in spinal nerve-ligated rats}

Unlike in sham-operated rats, 50- and 100- $\mu$ g atipamezole had no effect on punctate mechanical (2-way RM ANOVA $P=0.432$, $\left.\mathrm{F}_{2,20}=0.876\right)$ (Fig. 4A), heat (2-way RM ANOVA $P=0.848, \mathrm{~F}_{2,20}$ $=0.167$ ) (Fig. 4B), cooling (acetone: 1-way RM ANOVA $P=$ $0.226, F_{2,20}=1.604$; ethyl chloride: 1 -way RM ANOVA $P=$ 0.370, $F_{2,20}=1.047$ ) (Fig. 4C), and brush-evoked neuronal responses in the VPL of SNL rats (1-way RM ANOVA $P=0.858$, $F_{2,20}=0.154$ ) (Fig. 4D). Surprisingly, in contrast to the lack of effect on evoked responses, spontaneous activity (1-way RM ANOVA $\left.P=0.0039, F_{1.04,10.39}=13.415\right)($ Fig. $4 \mathrm{E})$ and burst

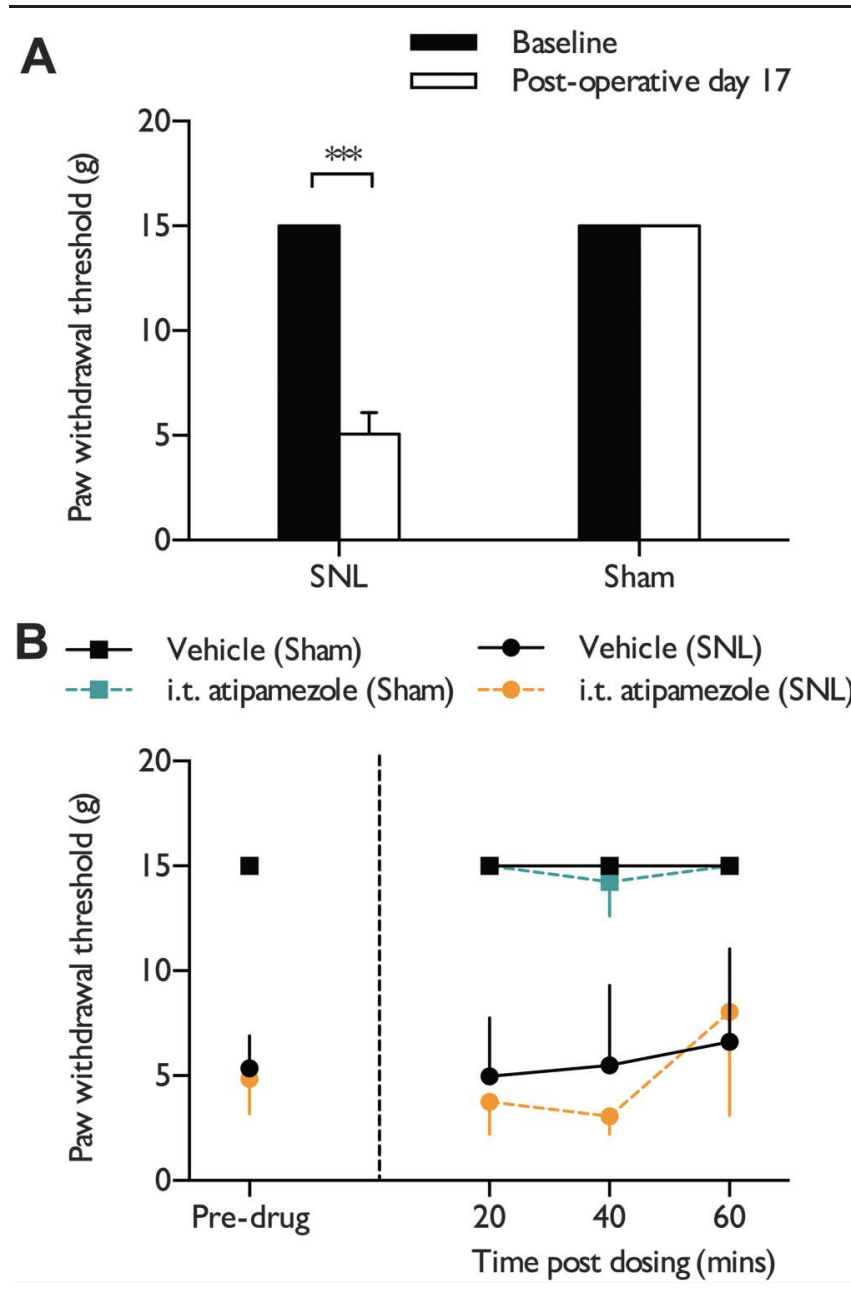

Figure 2. Spinal $\alpha_{2}$-adrenoceptor inhibition does not alter withdrawal thresholds in sham and SNL rats. Mechanically evoked withdrawal thresholds in sham $(n=29)$ and SNL rats $(n=14)$ before surgery and on postoperative day 17 (A). Paw withdrawal thresholds before and after intrathecal delivery of either vehicle (sham: $n=13, \mathrm{SNL} n=6$ ) or atipamezole (sham: $n=16$, SNL $\mathrm{n}=8$ ) (B). Data represent mean $\pm 95 \% \mathrm{Cl}$. ${ }^{\star \star \star} P<0.001$. Cl, confidence interval; i.t., intrathecal; SNL, spinal nerve-ligated. 
Table 1

Baseline characterisations of wide dynamic range neurones in the ventral posterolateral thalamus of naïve/sham and spinal nerve-ligated (SNL) rats.

\begin{tabular}{lccc}
\hline & Sham $\mathbf{n}=\mathbf{1 9}$ & SNL $\mathbf{n}=\mathbf{3 0}$ & Unpaired $t$ test $P=0.742$ \\
\hline Brush & $351 \pm 40.45$ & $367 \pm 26.20$ & 2-way ANOVA, $\mathrm{F}_{1,230}=16.51, P=0.00007$ \\
\hline $2 \mathrm{~g}$ & $44 \pm 10.20$ & $48 \pm 8.70$ & \\
\hline $8 \mathrm{~g}$ & $194 \pm 27.84$ & $275 \pm 22.17^{*}$ & \\
\hline $15 \mathrm{~g}$ & $304 \pm 36.30$ & $422 \pm 38.26^{*}$ & \\
\hline $26 \mathrm{~g}$ & $411 \pm 45.72$ & $574 \pm 43.34^{*}$ & 2 -way ANOVA, $\mathrm{F}_{1,188}=3.97, P=0.048$ \\
\hline $60 \mathrm{~g}$ & $549 \pm 53.98$ & $731 \pm 54.52^{*}$ & \\
\hline $35^{\circ} \mathrm{C}$ & $298 \pm 43.87$ & $296 \pm 28.48$ & \\
\hline $42^{\circ} \mathrm{C}$ & $393 \pm 56.13$ & $381 \pm 38.44$ & Unpaired $t$ test $P=0.239$ \\
\hline $45^{\circ} \mathrm{C}$ & $455 \pm 64.21$ & $431 \pm 40.19$ & Unpaired $t$ test $P=0.00003$ \\
\hline $48^{\circ} \mathrm{C}$ & $522 \pm 122.23$ & $758 \pm 55.17^{*}$ & Unpaired $t$ test $P=0.00012$ \\
\hline Acetone & $29 \pm 6.48$ & $52 \pm 14.15$ & Unpaired $t$ test $P=0.002$ \\
\hline Ethyl chloride & $123 \pm 19.20$ & $370 \pm 47.30 \ddagger$ & $22.73 \pm 3.76 \ddagger$ \\
\hline Spontaneous firing (spikes/s) & $5.45 \pm 0.90$ & $3.87 \pm 0.97 \dagger$ & \\
\hline Burst rate (bursts/s) & $0.47 \pm 0.20$ & & \\
\hline
\end{tabular}

Unless otherwise specified, data represent mean total evoked spikes $\pm 95 \% \mathrm{Cl}$.

${ }^{*} P<0.05$.

$\dagger P<0.01$.

$\ddagger P<0.001$

ANOVA, analysis of variance.

firing (1-way RM ANOVA $\left.P=0.00079, F_{2,20}=10.428\right)($ Fig. 4F) substantially increased after spinal delivery of atipamezole.

\subsection{Spinal $\alpha_{2}$-adrenoceptor inhibition induces conditioned place avoidance in sham but not spinal nerve-ligated rats}

In light of the aforementioned observations, we next examined whether inhibiting spinal $\alpha_{2}$-adrenoceptors produced avoidance learning behaviours in sham and SNL rats. The time spent in atipamezole $(20 \mu \mathrm{g} / 5 \mu \mathrm{L})$ and vehicle-paired chambers during preconditioning trials were comparable across groups. After conditioning, most sham-operated animals (7/10) displayed clear avoidance of the atipamezole-paired chamber, and a corresponding increase in the time spent in the vehicle-paired chamber was observed (2-way RM ANOVA $P=0.0033, F_{1,9}=$ 15.599) (Fig. 5A). By contrast, SNL rats displayed no preference for the vehicle- or atipamezole-paired chamber after a single conditioning trial (2-way RM ANOVA $P=0.502, F_{1,6}=0.511$ ) (Fig. 5B) or after 2 conditioning trials (data not shown). The difference scores (atipamezole-paired chamber) further illustrate the larger effect size in sham rats compared with SNL (unpaired Student's $t$ test, $t=2.54, d f=15, P=0.0227$ ) (Fig. 5C).

\subsection{Activation of spinal $\alpha_{2}$-adrenoceptors attenuates evoked and spontaneous firing in the VPL in sham and spinal nerve-ligated rats}

Spinal clonidine (50 and $100 \mu \mathrm{g}$ ), an $\alpha_{2}$-adrenoceptor agonist, dose dependently inhibited evoked and spontaneous thalamic neuronal firing. In sham rats, responses to punctate mechanical (2-way RM ANOVA $\left.P=0.000005, F_{2,14}=32.636\right)($ Fig. 6A) and heat stimuli (2-way RM ANOVA $P=0.00265, F_{2,14}=9.342$ ) (Fig. $6 \mathrm{~B})$ were reduced across intensities of stimulation. Responses to innocuous cooling were unaffected, although noxious coolingevoked responses were reduced by clonidine (acetone: 1-way RM ANOVA $P=0.163, F_{1.07,7.49}=2.399$; ethyl chloride: 1 -way
RM ANOVA $\left.P=0.0109, F_{2,14}=6.356\right)$ (Fig. 6C). We found weak evidence for an overall decrease in brush-evoked firing (1-way RM ANOVA $P=0.0411, \mathrm{~F}_{2,14}=4.044$, paired comparisons $P>$ 0.05) (Fig. 6D). Low rates of spontaneous firing were observed and were only inhibited at the highest dose tested (1-way RM ANOVA $\left.P=0.0171, F_{1.21,8.49}=8.12\right)$ (Fig. 6E). Likewise, the levels of burst firing were minimal but were not altered by clonidine (1-way RM ANOVA $P=0.115, F_{2,14}=2.529$ ) (Fig. 6F).

In SNL rats, spinal clonidine exhibited enhanced inhibitory effects at both doses tested, particularly on mechanical and heatevoked responses (Figs. 7A-F and Supplementary Table 1; available online at http://links.Iww.com/PAIN/A596). Neuronal responses to punctate mechanical (2-way RM ANOVA $P=$ $\left.0.000003, F_{2,14}=36.573\right)$ (Fig. 7A) and heat stimuli (2-way RM ANOVA $P=0.000046, F_{2,14}=22.11$ ) (Fig. 7B) were substantially decreased compared with baseline, again across intensities of stimulation. There was no overall effect on responses to innocuous cooling; however, noxious cold evoked markedly fewer spikes (acetone: 1-way RM ANOVA $P=0.092, F_{2,14}=$ 2.844; ethyl chloride: 1-way RM ANOVA $P=0.00786, F_{1.05,7.37}$ $=12.79$ ) (Fig. 7 C). Compared with sham rats, a greater inhibitory effect on brush-evoked responses was also notable (1-way RM ANOVA $\left.P=0.0173, F_{2,14}=5.5\right)$ (Fig. 7D). In addition, clonidine reduced levels of spontaneous firing at both doses (1-way RM ANOVA $\left.P=0.0131, F_{1.06,7.39}=10.337\right)$ (Fig. 7E), although the burst rate was only lower at the highest dose tested (1-way RM ANOVA $\left.P=0.0436, F_{2,14}=3.951\right)$ (Fig. 7F).

\subsection{Augmenting spinal noradrenergic tone with reboxetine modestly restores inhibitory control of evoked responses in spinal nerve-ligated rats}

Reboxetine (10 and $50 \mu \mathrm{g}$ ), administered spinally to SNL rats, reduced mechanically evoked neuronal responses in the VPL with greater effect on lower intensity stimuli compared with noxious stimuli (2-way RM ANOVA $P=0.0372, F_{2,20}=3.899$ ) 

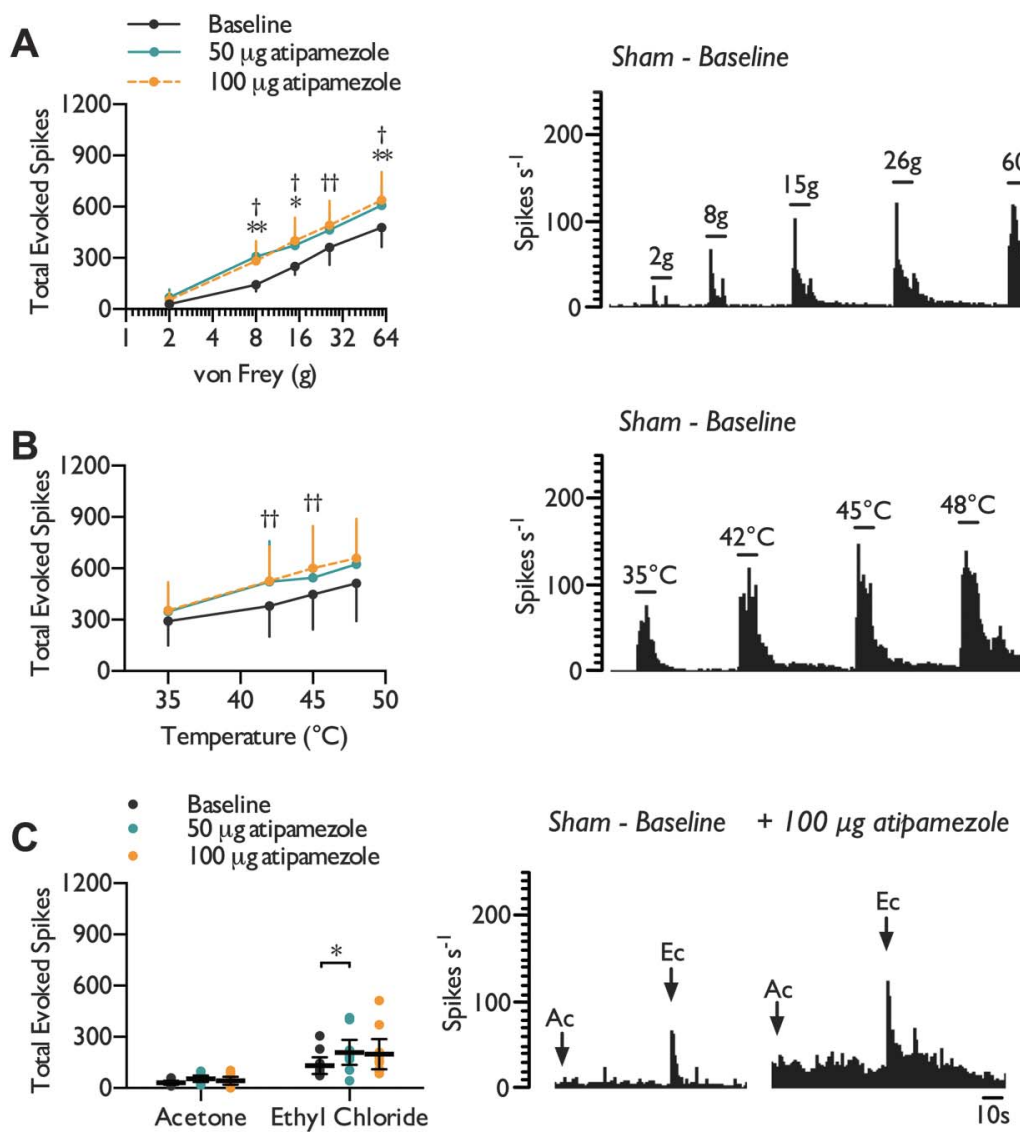

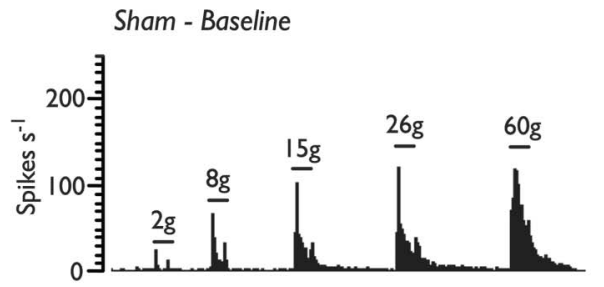

Sham - Baseline

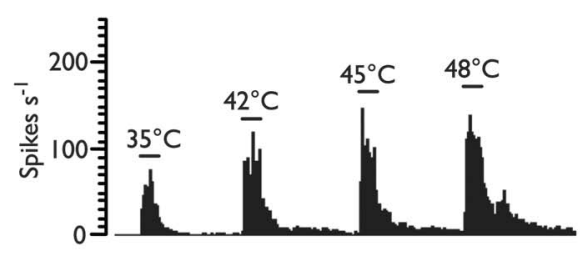

$+100 \mu \mathrm{g}$ atipamezole

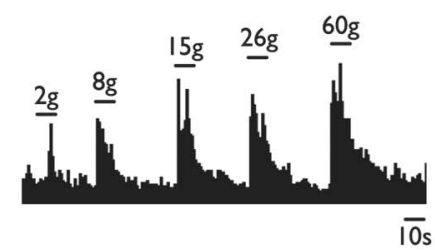

$+100 \mu \mathrm{g}$ atipamezole

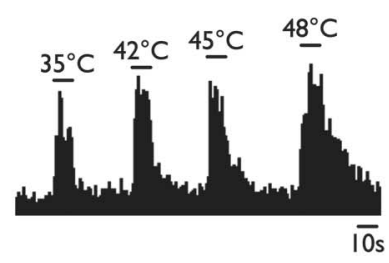

E

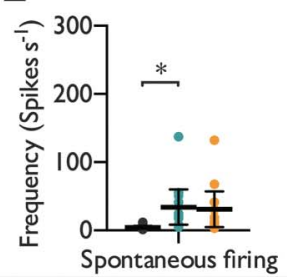

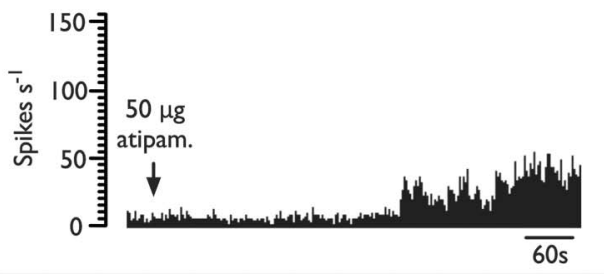
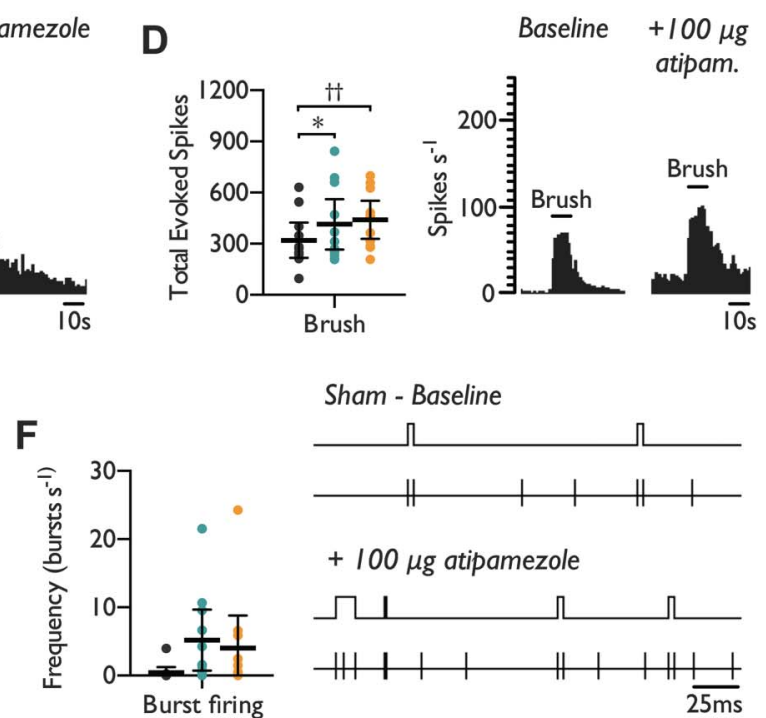

Figure 3. Inhibiting spinal $\alpha_{2}$-adrenoceptors increases stimulus-evoked and spontaneous firing in the VPL of naive/sham rats. Wide dynamic range (WDR) neuronal responses to punctate mechanical (A), heat (B), cold (C), dynamic brush (D) stimuli, and spontaneous (E) and burst firing rates (F), before and after spinal administration of atipamezole. Histogram and event mark traces represent typical single-unit responses. Data represent mean $\pm 95 \% \mathrm{Cl}, \mathrm{n}=11 \mathrm{neurones}$ from 8 rats. ${ }^{\star}$ Difference between baseline and $50-\mu \mathrm{g}$ atipamezole, tdifference between baseline and 100- $\mu \mathrm{g}$ atipamezole, ${ }^{\star} P<0.05,{ }^{\star \star} P<0.01$. Ac, acetone; Cl, confidence interval; Ec, ethyl chloride.

(Fig. 8A). Overall, heat-evoked responses were unaffected (2way RM ANOVA $\left.P=0.409, F_{2,20}=0.936\right)$ (Fig. 8B), although responses evoked by noxious cooling were inhibited (acetone: 1way $\mathrm{RM}$ ANOVA $P=0.842, \mathrm{~F}_{1.2,12.01}=0.68$; ethyl chloride: 1 way RM ANOVA $P=0.0346, F_{1.23,12.31}=5.249$ ) (Fig. $8 C$ ). In addition, there was weak evidence for a decrease in dynamic brush-evoked responses at the highest dose tested (1-way RM ANOVA $P=0.0276, F_{2,20}=4.317$, paired comparisons $P>$ 0.05) (Fig. 8D). In marked contrast to the effects of spinal clonidine, reboxetine affected neither spontaneous activity (1way RM ANOVA $\left.P=0.187, F_{1.19,11.86}=1.967\right)($ Fig. 8E) nor the burst rate (Fig. 8F) (1-way RM ANOVA $P=0.666, F_{2,20}=0.415$ ).

\section{Discussion}

In this article, we describe how descending noradrenergic inhibition of spinal excitability impacts sensory coding in the ventral posterior thalamus. These data support that distinct mechanisms mediate inhibition of evoked and spontaneous neuronal activity after nerve injury. Furthermore, this distinction in inhibitory control has consequences for the actions of analgesics targeted at enhancing endogenous inhibitory tone in neuropathic conditions. To our knowledge, we also demonstrate for the first time that negating spinal noradrenergic activity through $\alpha_{2^{-}}$ adrenoceptors in sham rats, ie, in the absence of neuropathic injury, produces a negative affective state.

Noradrenaline in the spinal cord is derived from nuclei within the dorsolateral pontine tegmentum. ${ }^{6} \mathrm{NK} 1$-positive projection neurones of the superficial dorsal horn are the origin of a spinobulbospinal circuit, which through the parabrachial and dorsal raphe nuclei can activate descending facilitation. ${ }^{58,67}$ Ablation of these neurones reveals that this population also drives descending inhibition through a pontospinal loop; ${ }^{55}$ however, the resultant net decrease in spinal neuronal excitability indicates facilitation 


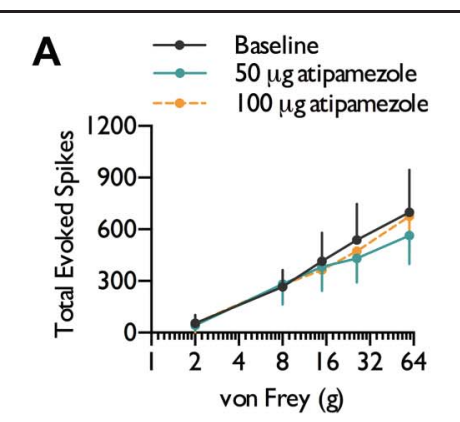

E

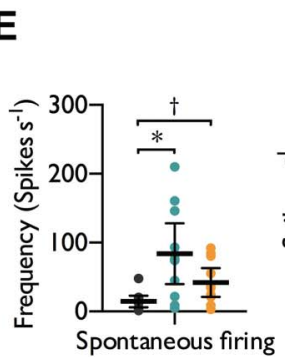

B

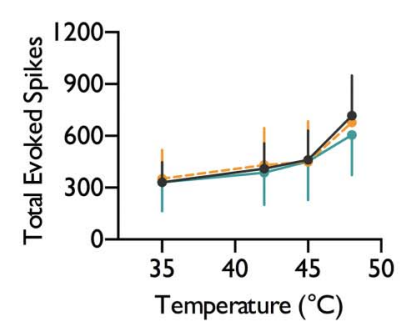

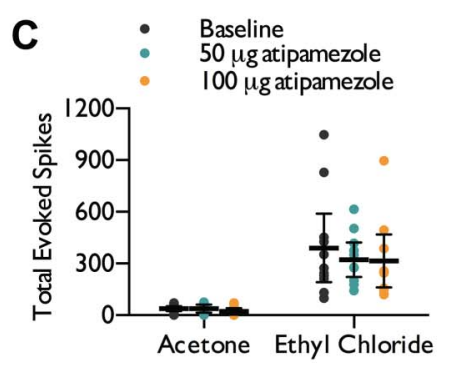

D

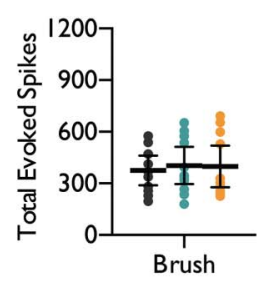

Figure 4. Inhibiting spinal $\alpha_{2}$-adrenoceptors selectively increases spontaneous firing in the VPL of SNL rats. Wide dynamic range (WDR) neuronal responses to punctate mechanical (A), heat (B), cold (C), dynamic brush (D) stimuli, and spontaneous (E) and burst firing rate (F), before and after spinal administration of atipamezole. Histogram and event mark traces represent typical single-unit responses. Data represent mean $\pm 95 \% \mathrm{Cl}, \mathrm{n}=11 \mathrm{neurones}$ from 7 rats. ${ }^{\star}$ Difference between baseline and 50- $\mu \mathrm{g}$ atipamezole, tdifference between baseline and 100- $\mu \mathrm{g}$ atipamezole, ${ }^{\star} P<0.05$, ${ }^{\star *} P<0.01$. Cl, confidence interval; SNL, spinal nerve-ligated.

predominates. Significant engagement of noradrenergic inhibitory pathways is apparent during extended periods of nociceptive activity, ${ }^{20,39}$ acutely after an inflammatory insult or nerve injury, ${ }^{7,28}$ and in response to pruritogens. ${ }^{18,19}$ By contrast, there is a paucity of compelling evidence for the existence of tonic noradrenergic control of spinal excitability. Contradictory findings propose that either minimal/no basal activity exists within descending noradrenergic pathways, ${ }^{25,29,38,41,71}$ or that, these spinally directed projections tonically suppress reflex responses and spinal neuronal responses to low-intensity stimuli. ${ }^{24,54,55,59}$

We provide evidence of tonic descending inhibitory drive, which exerts inhibitory effects across sensory modalities and intensities of stimulation through $\alpha_{2}$-adrenoceptors, whereas in neuropathic rats, noradrenergic inhibition is partially diminished and discriminates between spontaneous and evoked activity. Previously, spinally administered atipamezole was demonstrated to increase spontaneous and evoked activity of dorsal horn lamina VNI WDR neurones in sham rats, ${ }^{54}$ and corresponds with the changes in neuronal excitability observed here in the VPL.
However, in SNL rats, atipamezole had no effect on either evoked or spontaneous spinal neuronal activity. ${ }^{54}$ It has been reported that dorsal horn neurones without receptive fields can exhibit high levels of spontaneous firing after peripheral nerve injury. ${ }^{11,65}$ Likewise, after amputation or in deafferentation pain, thalamic neurones without receptive fields but within the region of representation of the injury can exhibit high rates of burst and spontaneous firing. ${ }^{35,36,57,72}$ We hypothesise that after peripheral nerve injury, ectopic neuronal events in denervated regions of the dorsal horn are actively supressed through a postsynaptic $\alpha_{2^{-}}$ adrenoceptor-dependent mechanism and disinhibition by spinal atipamezole results in increased spontaneous activity in the VPL. By contrast, in regions of the dorsal horn where peripheral innervation is conserved despite nerve injury, descending noradrenergic inhibitory influences seem minimal as is evident by the lack of change in evoked neuronal responses in the VPL and dorsal horn after spinal atipamezole application (Fig. 9). Our data suggest that, akin to data on diffuse noxious inhibitory controls, ${ }^{3}$ the descending noradrenergic pathway is less active
A

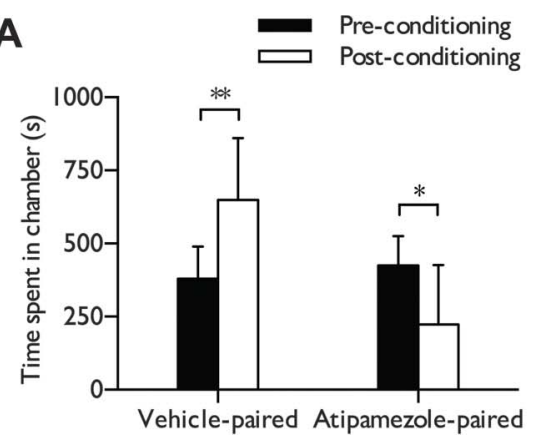

B

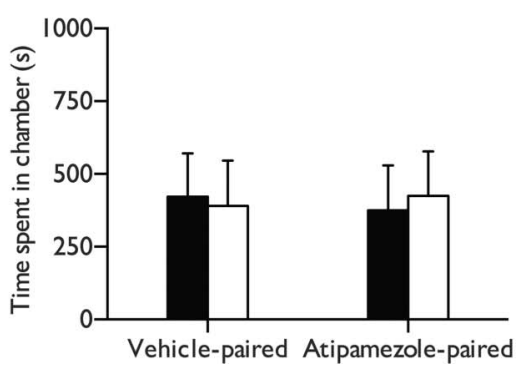

C

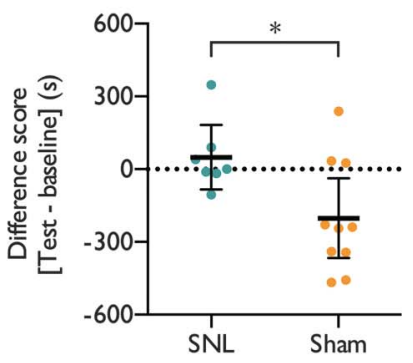

Figure 5. Inhibiting spinal $\alpha_{2}$-adrenoceptors produces avoidance learning behaviour in sham but not SNL rats. Time spent in respective drug-paired chambers before and after conditioning with vehicle and atipamezole in sham rats $(n=10)(A)$. Time spent in respective drug-paired chambers before and after conditioning with vehicle and atipamezole in SNL rats $(n=7)(B)$. Difference score (atipamezole-paired chamber) for SNL and sham rats $(C)$. Data represent mean $\pm 95 \%$ Cl. ${ }^{*} P$ $<0.05,{ }^{\star \star} P<0.01$. Cl, confidence interval; SNL, spinal nerve-ligated. 


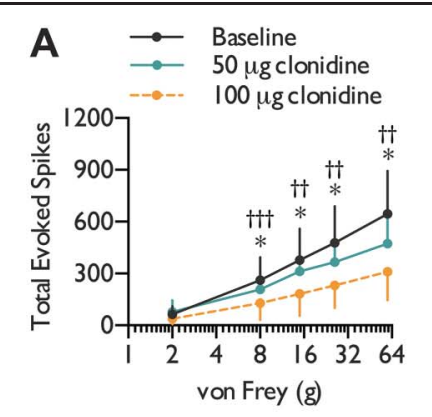

B

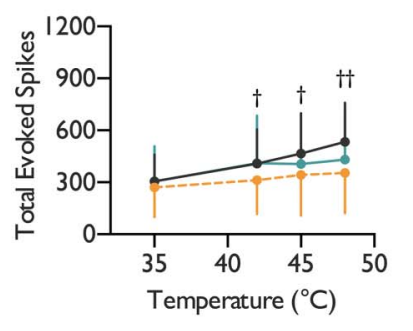

$\begin{array}{ll}\text { C } \quad \text { Baseline } \\ & 50 \mu \mathrm{g} \text { clonidine } \\ & 100 \mu \mathrm{g} \text { clonidine }\end{array}$
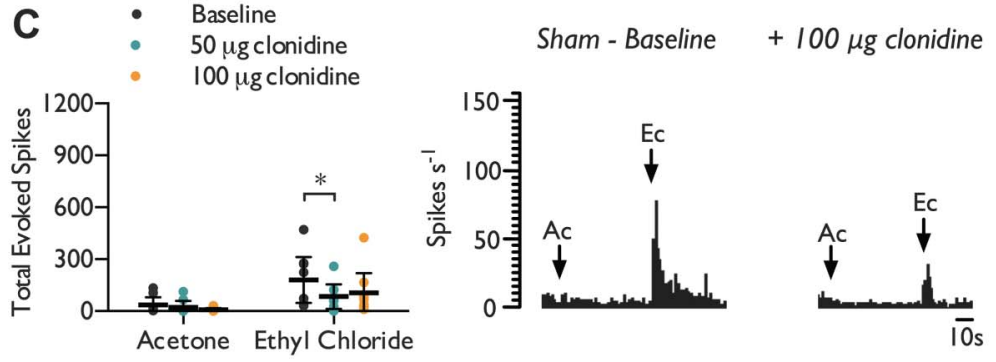
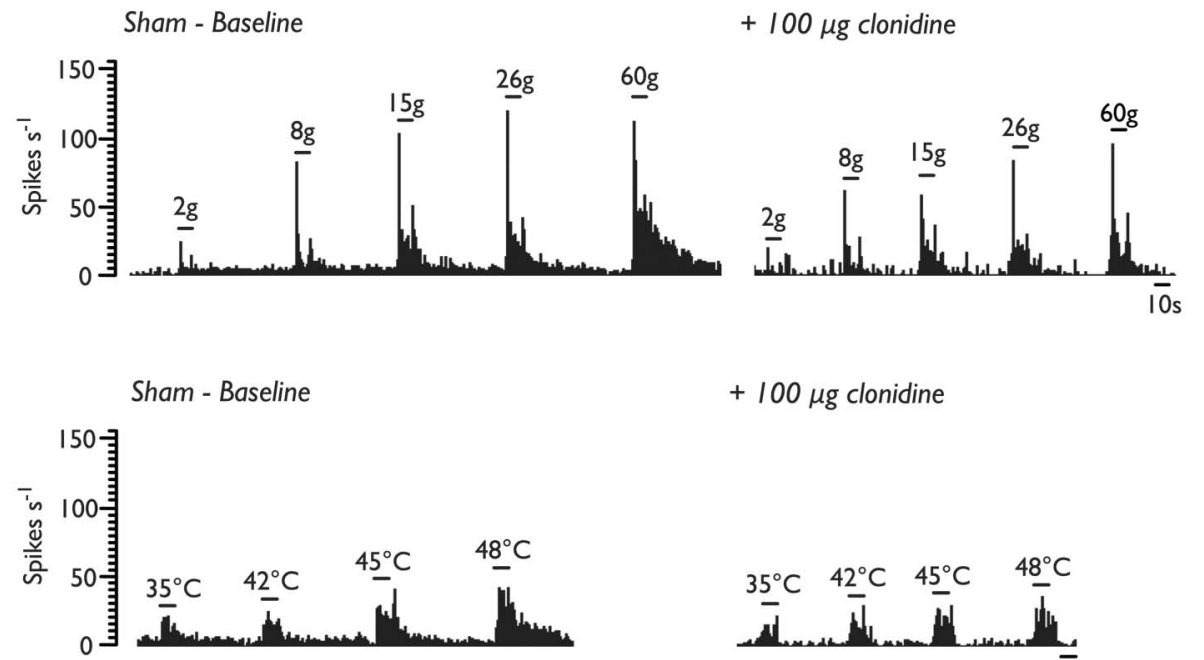

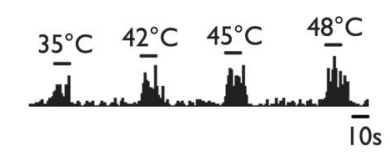

$\mathbf{E}$

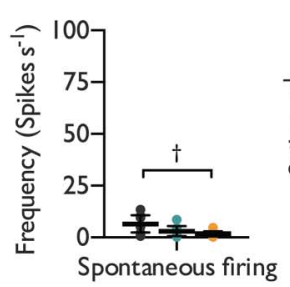

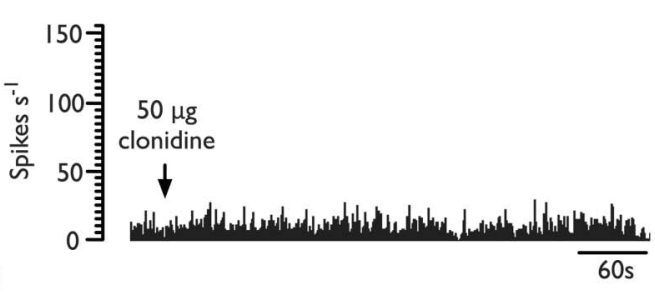

$\mathbf{F}$

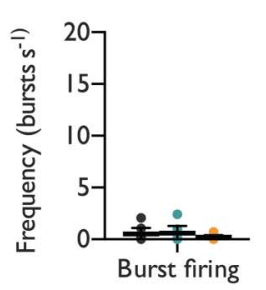

Sham - Baseline

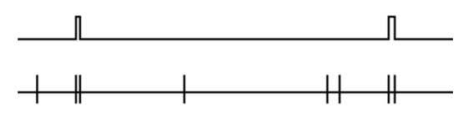

$+100 \mu \mathrm{g}$ clonidine

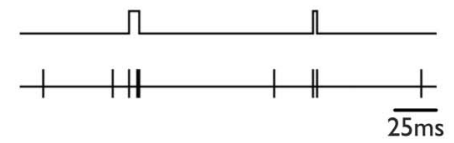

Figure 6. Activating spinal $\alpha_{2}$-adrenoceptors reduces stimulus-evoked and spontaneous firing in the VPL of sham rats. Wide dynamic range (WDR) neuronal responses to punctate mechanical (A), heat (B), cold (C), dynamic brush (D) stimuli, and spontaneous (E) and burst firing rate (F), before and after spinal administration of clonidine. Histogram and event mark traces represent typical single-unit responses. Data represent mean $\pm 95 \% \mathrm{Cl}, \mathrm{n}=8 \mathrm{neurones}$ from 5 rats. ${ }^{*}$ Difference between baseline and $50-\mu \mathrm{g}$ clonidine, tdifference between baseline and 100- $\mu \mathrm{g}$ clonidine, ${ }^{*} P<0.05,{ }^{\star \star} P<0.01,{ }^{\star \star \star} P<0.001$. Ac, acetone; Ec, ethyl chloride; $\mathrm{Cl}$, confidence interval.

after neuropathy but remains intact. The conserved integrity of this pathway is further illustrated by the selective activation of spinally projecting locus coeruleus neurones because antinociceptive effects can still be produced in neuropathic states. ${ }^{25}$

Both animal and human data suggest that sensory and affective dimensions of pain are partially separable and implicate the anterior cingulate cortex in mediating the aversive qualities of pain. ${ }^{30,53,56}$ After sham surgery, conditioned avoidance behaviours were precipitated by block of spinal $\alpha_{2}$-adrenoceptors, which would be consistent with disinhibition within medial projection pathways converging onto the anterior cingulate cortex. The concurrent increase in spontaneous activity within the STT-VP-S ${ }_{1-2}$ pathway may reflect the sensory component, although it is unclear whether this represents noxious inputs. By contrast, intrathecal atipamezole failed to induce CPA in SNL rats. As neuropathic animals experience an ongoing aversive pain state, an increase in spontaneous firing within lateral but not medial pathways could underlie a failure to drive avoidance learning behaviours because sensory but not affective processing is enhanced by inhibition of spinal $\alpha_{2}$-adrenoceptors. The effects of atipamezole on withdrawal thresholds are comparable with our previous observations with intrathecal yohimbine. ${ }^{12}$ The disparity between the effect of intrathecal atipamezole on reflex withdrawal responses and evoked neuronal correlates likely reflects differences in processing mechanisms. Spinally mediated reflex withdrawals are surmised to represent sensory processing, but it is difficult to dissociate the sensory and motor components. In sham rats, the observed leftward shift in the stimulus-response relationship of WDR neurones was perhaps not sufficient to elicit enhanced motor responses. Consequently, the sensorimotor endpoints should be interpreted cautiously, and the neuronal measures may provide a more sensitive readout of subtle changes in sensory processing. 


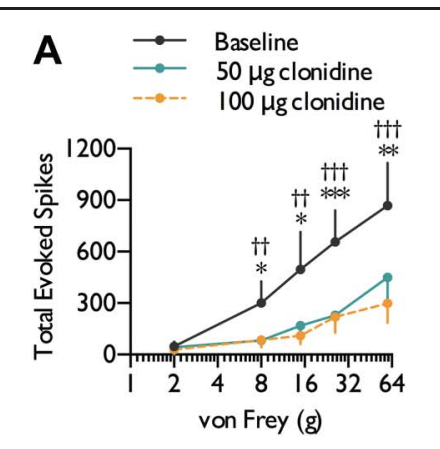

B

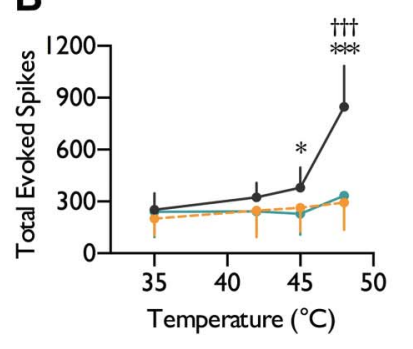

C Baseline

- $50 \mu$ g clonidine

$100 \mu \mathrm{g}$ clonidine
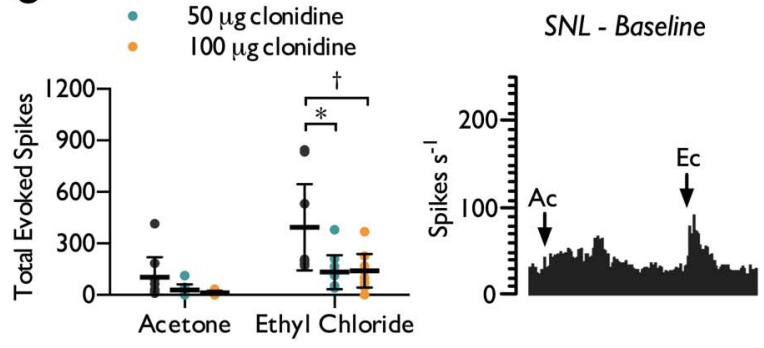

$+100 \mu \mathrm{g}$ clonidine

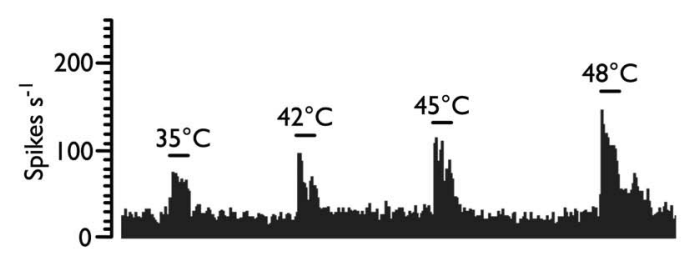

$+100 \mu \mathrm{g}$ clonidine

$+100 \mu \mathrm{g}$ clonidine

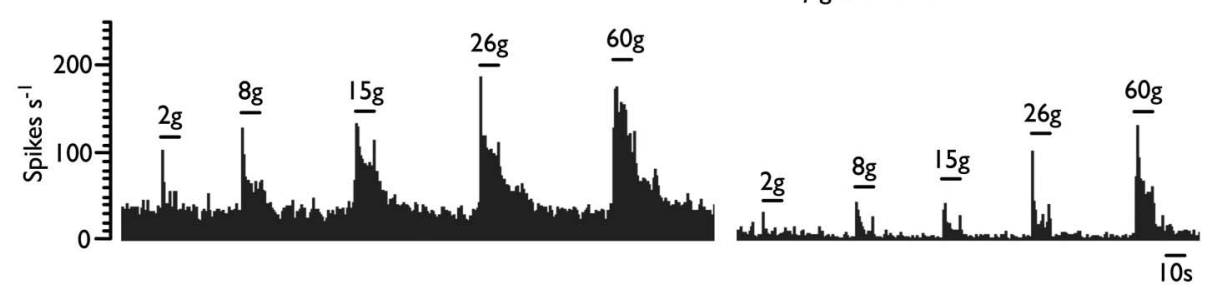

E

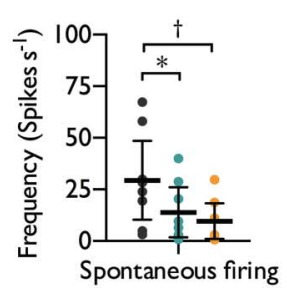

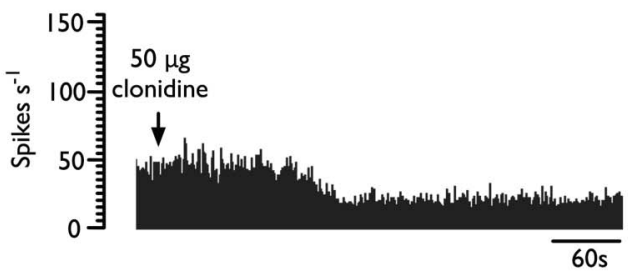

F

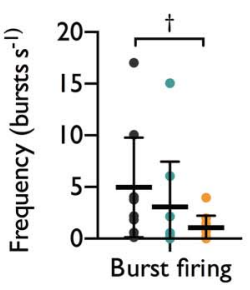

D

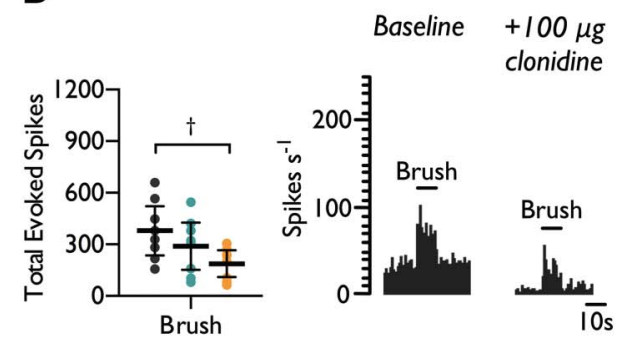

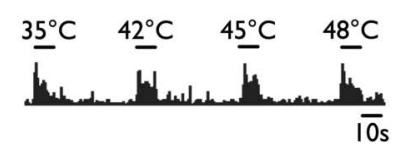

Figure 7. Activating spinal $\alpha_{2}$-adrenoceptors reduces stimulus-evoked and spontaneous firing in the VPL of SNL rats. Wide dynamic range (WDR) neuronal responses to punctate mechanical (A), heat (B), cold (C), dynamic brush (D) stimuli, and spontaneous (E) and burst firing rate (F), before and after spinal administration of clonidine. Histogram and event mark traces represent typical single-unit responses. Data represent mean $\pm 95 \% \mathrm{Cl}, \mathrm{n}=8 \mathrm{neurones}$ from 6 rats. ${ }^{\star}$ Difference between baseline and $50-\mu \mathrm{g}$ clonidine, tdifference between baseline and 100- $\mu \mathrm{g}$ clonidine, ${ }^{\star} P<0.05,{ }^{\star \star} P<0.01,{ }^{\star \star *} P<0.001$. Ac, acetone; Ec, ethyl chloride; Cl, confidence interval; SNL, spinal nerve-ligated.

We further examined the effects of clinically used approaches to augmenting spinal noradrenergic tone: enhancing synaptic noradrenaline and directly activating $\alpha_{2}$-adrenoceptors. Diminished inhibitory control of evoked responses in neuropathic animals was weakly restored by spinal reboxetine in a modalityselective manner, but spontaneous activity was unaffected. The latter observation may reflect a "ceiling effect" as blocking reuptake of noradrenaline fails to enhance the high levels of basal activity within this pathway, which were revealed by atipamezole (Fig. 9). The modality-selective inhibition of mechanical and cold-evoked responses and weaker effects on heatevoked responses implies preferential engagement of inhibitory receptors on subsets of primary afferent terminals. In the dorsal horn, these are predominantly $\alpha_{2 A}$ receptors that colocalise with substance $P,{ }^{62}$ and $\alpha_{2 A}$ receptors are differentially upregulated in fibre subtypes after injury. ${ }^{5}$ Altered receptor density could in turn affect the ability of noradrenaline to inhibit A $\delta$ - and C-fibreevoked transmission. ${ }^{31}$ It is also possible that these modest inhibitory effects are influenced by descending serotonergic facilitatory drive because, in neuropathic states, increased spinal $5-\mathrm{HT}_{3}$ receptor activation can mask low levels of residual noradrenergic inhibition. ${ }^{3}$

Spinal clonidine has been used clinically as an adjunct or in isolation for amelioration of evoked and ongoing pain, ${ }^{16}$ and can be beneficial in patients with refractory cancer pain particularly those with neuropathic characteristics. ${ }^{15}$ In sham and SNL rats, clonidine exhibited inhibitory effects across sensory modalities and intensity of stimulus, and would be consistent with a predominantly postsynaptic inhibitory effect in the dorsal horn. Both spinally applied noradrenaline and clonidine induce postsynaptic 


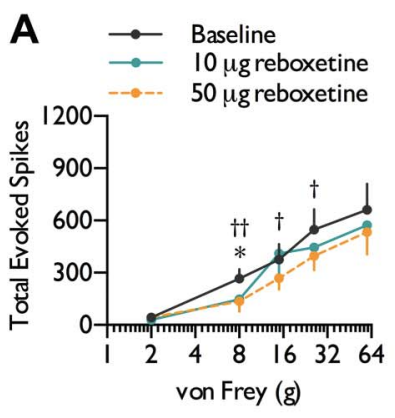

B

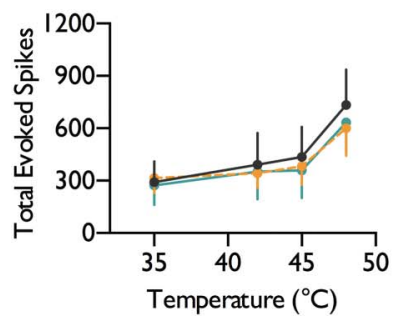

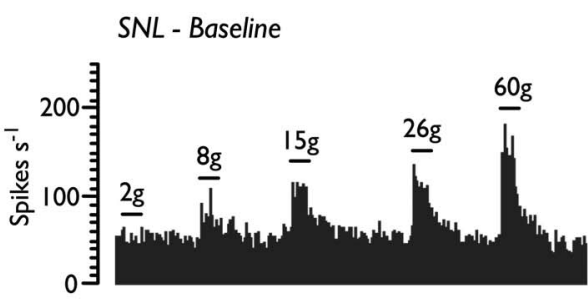

SNL - Baseline

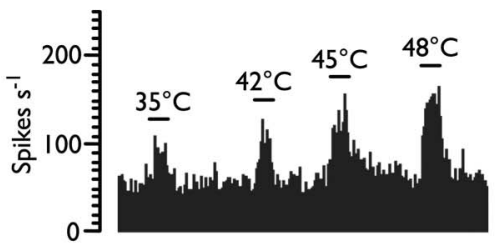

$+50 \mu \mathrm{g}$ reboxetine

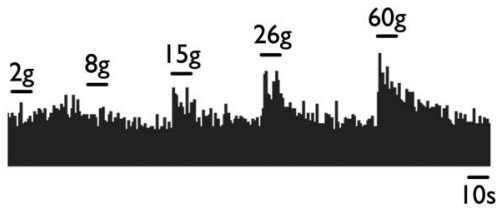

$+50 \mu \mathrm{g}$ reboxetine
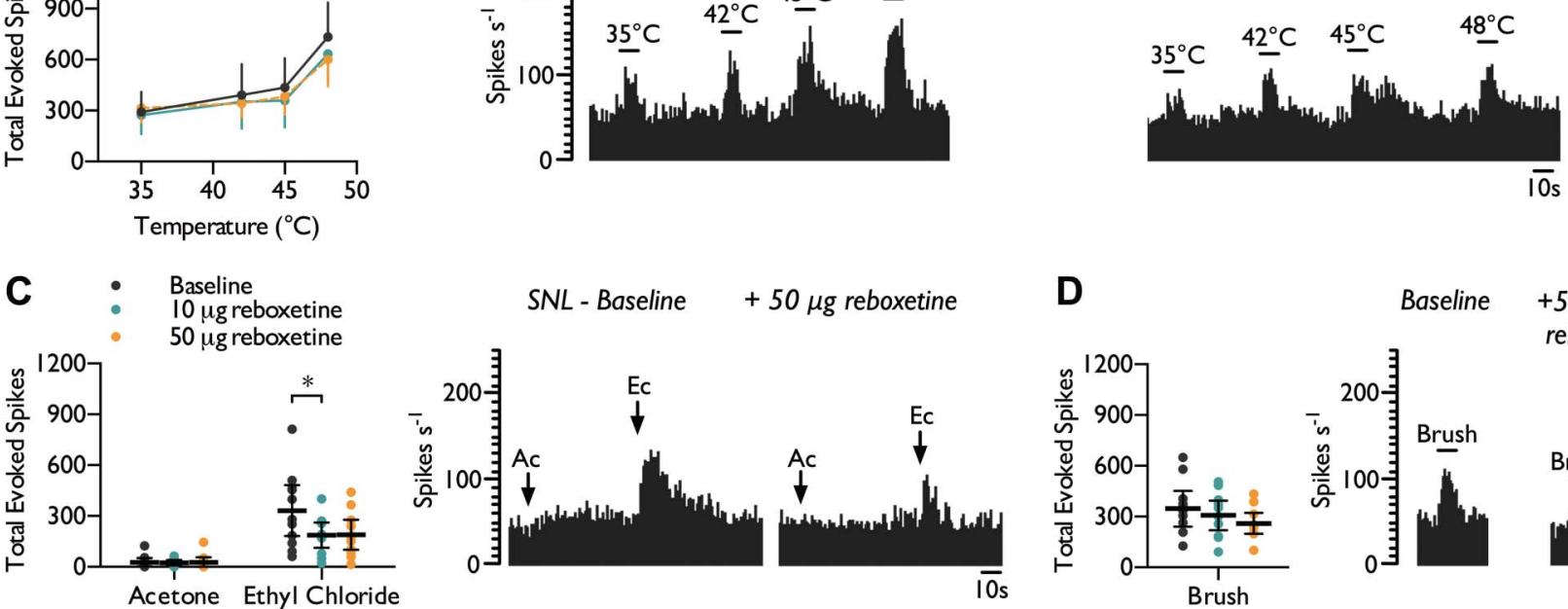

D
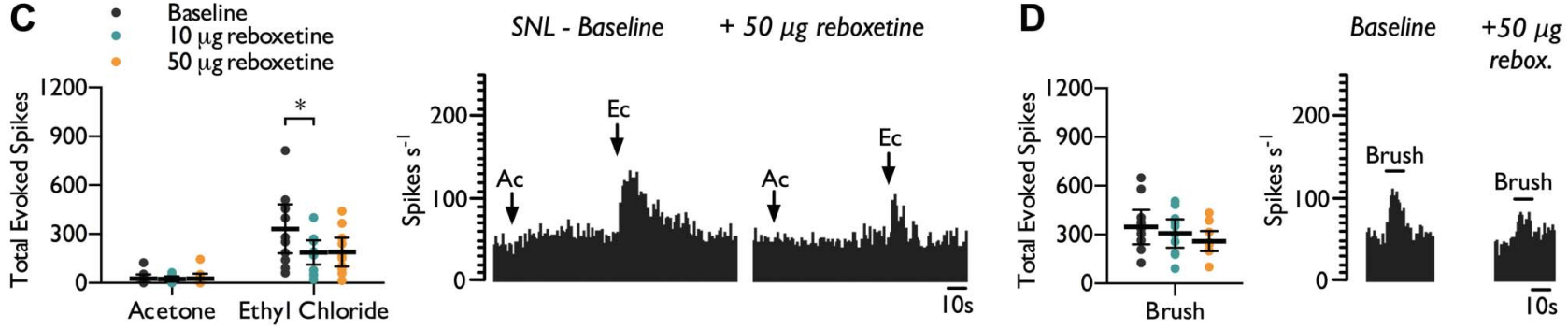

E

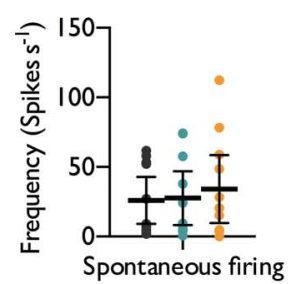

F

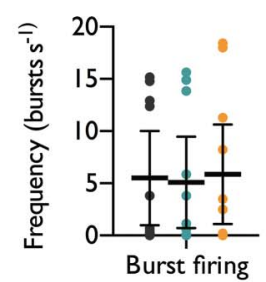

SNL - Baseline

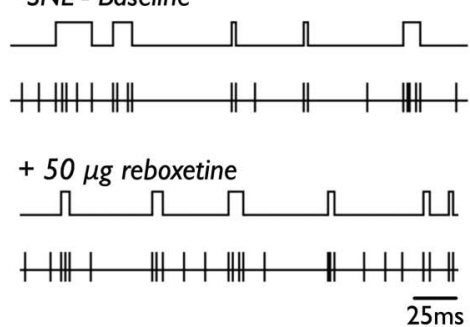

Figure 8. Blocking spinal noradrenaline reuptake reduces stimulus-evoked firing in the VPL of SNL rats. Wide dynamic range (WDR) neuronal responses to punctate mechanical $(A)$, heat $(B)$, cold $(C)$, dynamic brush (D) stimuli, and spontaneous $(E)$ and burst firing rate $(F)$, before and after spinal administration of reboxetine. Histogram and event mark traces represent typical single-unit responses. Data represent mean $\pm 95 \% \mathrm{Cl}, \mathrm{n}=11$ neurones from 7 rats. ${ }^{\star} \mathrm{Difference}$ between baseline and 10- $\mu \mathrm{g}$ reboxetine, tdifference between baseline and $50-\mu \mathrm{g}$ reboxetine, ${ }^{\star} P<0.05,{ }^{\star \star} P<0.01$. Ac, acetone; $\mathrm{Cl}$, confidence interval; Ec, ethyl chloride; SNL, spinal nerve-ligated.

outward currents in superficial dorsal horn neurones in vivo, in addition to decreasing the frequency of pinch-evoked excitatory postsynaptic currents. ${ }^{61}$ Presynaptic inhibitory effects can be mediated through $\alpha_{2 \mathrm{~A}}$ receptors on primary afferents, ${ }^{62} \alpha_{2 \mathrm{C}}$ receptors expressed by excitatory interneurones, ${ }^{47}$ and at higher doses, $\alpha_{1}$ receptors on inhibitory interneurones are potentially activated. ${ }^{2}$ The increased potency of $\alpha_{2}$-adrenoceptor agonists in neuropathic states implies plasticity within spinal circuits after an injury. ${ }^{66,76}$ In particular, this could relate to increases in $\alpha_{2}$ adrenoceptor density and enhanced receptor coupling to Gproteins to compensate for a loss of inhibitory tone due to hypoactivity in the descending pathway. 4,5,63 Intrathecal clonidine alleviated ongoing pain and concomitantly activated reward pathways in SNL, but not sham-operated rats, ${ }^{32,40,74}$ and similarly, intrathecal reboxetine produced conditioned place preference in a manner dependent on pathophysiological state. ${ }^{27}$
Speculatively, intrathecal clonidine and reboxetine may have distinct actions on sensory and affective processing. However, a potential confound of this study is the rapid absorption of clonidine; inhibitory effects could be attributed to supraspinal mechanisms as direct actions within the locus coeruleus will impact both ascending and descending modulation of sensory transmission. 22,42,81

In addition to proving a readout of "bottom-up" processing mechanisms, thalamic relay neurones are subjected to "topdown" processing. Corticofugal outputs can modulate sensory transmission, ${ }^{43}$ and thalamo-cortical neurones send collaterals to the thalamic reticular nucleus, which in turn exerts GABAergic inhibitory influences on the thalamus. ${ }^{52}$ Burst propensity can be regulated by tonic $\mathrm{GABA}_{\mathrm{A}}$ receptor activation, ${ }^{10}$ and the changes in burst firing rates observed in this study may largely be determined by these circuits as a consequence of altered 


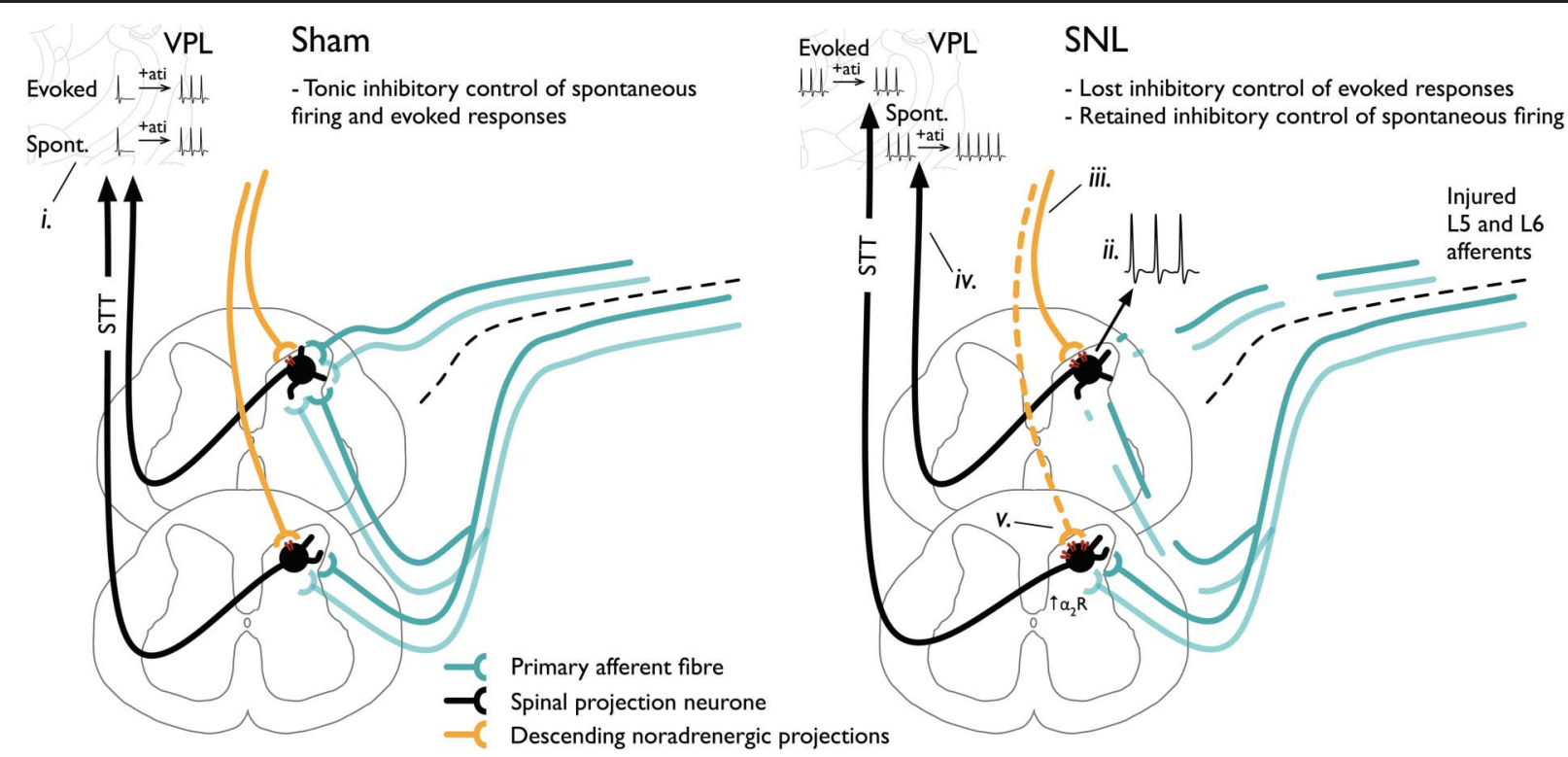

Figure 9. Schematic depicting proposed mechanism of noradrenergic control after peripheral nerve injury. In sham animals, the descending noradrenergic system exerts tonic inhibitory control of spontaneous and evoked firing, revealed in the VPL after spinal $\alpha_{2}$-adrenoceptor inhibition with atipamezole (i). After neuropathic injury, denervated spinal neurones can exhibit high levels of spontaneous firing (ii), which continue to be subjected to descending inhibitory control (iii). Disinhibition by spinally administered atipamezole results in elevated spontaneous activity in VPL (iv), whereas dorsal horn regions with conserved input have diminished descending control of spontaneous and evoked activity (v). ati, intrathecal atipamezole; spont, spontaneous firing; SNL, spinal nerve-ligated; STT, spinothalamic tract; VPL, ventral posterolateral thalamus.

ascending spinal output. In addition, noradrenergic projections from the midbrain can influence neuronal excitability. In slice preparations, noradrenaline mediates a switch from burst to tonic firing patterns. ${ }^{49}$ This pathway provides a putative mechanism by which the state of alertness or arousal can influence sensory transmission. ${ }^{14}$ It is also possible that inhibition of the pontospinal pathway leads to an imbalance in the multilevel modulation by the noradrenergic system and alters ascending sensory signalling.

In conclusion, these data may have implications for the clinical approach of enhancing endogenous inhibitory activity. For those patients with small and/or large fibre neuropathy, where deafferentation of spinal neurones is likely, a significant component of ongoing pain may be driven by ectopically firing spinal neurones. Overall, patient outcomes for SNRIs could remain poor given the inability of spinal reboxetine to supress aberrant spontaneous neuronal activity in this model. Interestingly, inefficient CPM in diabetic neuropathy patients correlated with relative preservation of large afferents and advocates continued sensory profiling on this basis because there is an increased likelihood of benefit from SNRIs in this patient group. ${ }^{79}$ Subtype-specific $\alpha_{2}$-adrenoceptor agonists could be the focus of future investigations to assess whether spinal and supraspinal mechanisms can be dissociated.

\section{Conflict of interest statement}

A.H. Dickenson has received research funding and honoraria for lectures from Grünenthal $\mathrm{GmbH}$. The remaining authors have no conflict of interest to declare.

This study was funded by the Wellcome Trust Pain Consortium (102645-Defining pain circuitry in health and disease) and the National Institutes of Health (DA 041809).

\section{Acknowledgments}

Author contributions: R. Patel and A.H. Dickenson, conception and design of study; R. Patel and C. Qu, performed experiments;
R. Patel and J.Y. Xie, analysed data; R. Patel, A.H. Dickenson, J.Y. Xie, and F. Porreca, interpreted results of experiments; R. Patel, prepared figures; R. Patel, drafted manuscript; R. Patel, A.H. Dickenson, J.Y. Xie, and F. Porreca, edited and revised manuscript. All authors read and approved the final manuscript.

\section{Appendix A. Supplemental digital content}

Supplemental digital content associated with this article can be found online at http://links.Iww.com/PAIN/A596.

\section{Article history:}

Received 11 January 2018

Received in revised form 4 May 2018

Accepted 7 May 2018

Available online 31 May 2018

\section{References}

[1] Apkarian AV, Shi T. Squirrel monkey lateral thalamus. I. Somatic nociresponsive neurons and their relation to spinothalamic terminals. J Neurosci 1994;14(11 pt 2):6779-95.

[2] Baba H, Shimoji K, Yoshimura M. Norepinephrine facilitates inhibitory transmission in substantia gelatinosa of adult rat spinal cord (part 1): effects on axon terminals of GABAergic and glycinergic neurons. Anesthesiology 2000;92:473-84.

[3] Bannister K, Patel R, Goncalves L, Townson L, Dickenson AH. Diffuse noxious inhibitory controls and nerve injury: restoring an imbalance between descending monoamine inhibitions and facilitations. PAIN 2015; 156:1803-11.

[4] Bantel C, Eisenach JC, Duflo F, Tobin JR, Childers SR. Spinal nerve ligation increases alpha2-adrenergic receptor G-protein coupling in the spinal cord. Brain Res 2005;1038:76-82.

[5] Birder LA, Perl ER. Expression of alpha2-adrenergic receptors in rat primary afferent neurones after peripheral nerve injury or inflammation. J Physiol 1999;515(pt 2):533-42.

[6] Bruinstroop E, Cano G, Vanderhorst VG, Cavalcante JC, Wirth J, SenaEsteves M, Saper CB. Spinal projections of the A5, A6 (locus coeruleus), and A7 noradrenergic cell groups in rats. J Comp Neurol 2012;520: 1985-2001. 
[7] Burnham LJ, Dickenson AH. The antinociceptive effect of milnacipran in the monosodium iodoacetate model of osteoarthritis pain and its relation to changes in descending inhibition. J Pharmacol Exp Ther 2013;344: 696-707.

[8] Chaplan SR, Bach FW, Pogrel JW, Chung JM, Yaksh TL. Quantitative assessment of tactile allodynia in the rat paw. J Neurosci Methods 1994; 53:55-63.

[9] Chapman V, Suzuki R, Dickenson AH. Electrophysiological characterization of spinal neuronal response properties in anaesthetized rats after ligation of spinal nerves L5-L6. J Physiol 1998;507(pt 3):881-94.

[10] Cope DW, Hughes SW, Crunelli V. GABAA receptor-mediated tonic inhibition in thalamic neurons. J Neurosci 2005;25:11553-63.

[11] Dalal A, Tata M, Allegre G, Gekiere F, Bons N, Albe-Fessard D. Spontaneous activity of rat dorsal horn cells in spinal segments of sciatic projection following transection of sciatic nerve or of corresponding dorsal roots. Neuroscience 1999;94:217-28.

[12] De Felice M, Sanoja R, Wang R, Vera-Portocarrero L, Oyarzo J, King T, Ossipov MH, Vanderah TW, Lai J, Dussor GO, Fields HL, Price TJ, Porreca F. Engagement of descending inhibition from the rostral ventromedial medulla protects against chronic neuropathic pain. PAIN 2011;152:2701-9.

[13] Demant DT, Lund K, Vollert J, Maier C, Segerdahl M, Finnerup NB, Jensen TS, Sindrup SH. The effect of oxcarbazepine in peripheral neuropathic pain depends on pain phenotype: a randomised, doubleblind, placebo-controlled phenotype-stratified study. PAIN 2014;155: 2263-73.

[14] Devilbiss DM, Waterhouse BD. The effects of tonic locus ceruleus output on sensory-evoked responses of ventral posterior medial thalamic and barrel field cortical neurons in the awake rat. J Neurosci 2004;24: 10773-85.

[15] Eisenach JC, DuPen S, Dubois M, Miguel R, Allin D. Epidural clonidine analgesia for intractable cancer pain. The Epidural Clonidine Study Group. PAIN 1995;61:391-9.

[16] Eisenach JC, De Kock M, Klimscha W. $\alpha 2$-Adrenergic agonists for regional anesthesia. A clinical review of clonidine (1984-1995). Anesthesiology 1996;85:655-74.

[17] Finnerup NB, Attal N, Haroutounian S, McNicol E, Baron R, Dworkin RH, Gilron I, Haanpaa M, Hansson P, Jensen TS, Kamerman PR, Lund K, Moore A, Raja SN, Rice AS, Rowbotham M, Sena E, Siddall P, Smith BH, Wallace M. Pharmacotherapy for neuropathic pain in adults: a systematic review and meta-analysis. Lancet Neurol 2015;14:162-73.

[18] Gotoh Y, Andoh T, Kuraishi Y. Noradrenergic regulation of itch transmission in the spinal cord mediated by alpha-adrenoceptors. Neuropharmacology 2011;61:825-31.

[19] Gotoh Y, Omori Y, Andoh T, Kuraishi Y. Tonic inhibition of allergic itch signaling by the descending noradrenergic system in mice. J Pharmacol Sci 2011;115:417-20.

[20] Green GM, Lyons L, Dickenson AH. Alpha2-adrenoceptor antagonists enhance responses of dorsal horn neurones to formalin induced inflammation. Eur J Pharmacol 1998;347:201-4.

[21] Guilbaud G, Benoist JM, Jazat F, Gautron M. Neuronal responsiveness in the ventrobasal thalamic complex of rats with an experimental peripheral mononeuropathy. J Neurophysiol 1990;64:1537-54.

[22] Guo TZ, Jiang JY, Buttermann AE, Maze M. Dexmedetomidine injection into the locus ceruleus produces antinociception. Anesthesiology 1996; 84:873-81.

[23] Hains BC, Saab CY, Waxman SG. Alterations in burst firing of thalamic VPL neurons and reversal by $\mathrm{Na}(\mathrm{V}) 1.3$ antisense after spinal cord injury. J Neurophysiol 2006;95:3343-52.

[24] Harris J, Clarke RW. Motor and cardiovascular effects of selective alpha 2-adrenoceptor antagonists in the decerebrated rabbit. Eur J Pharmacol 1993:237:323-8.

[25] Hirschberg S, Li Y, Randall A, Kremer EJ, Pickering AE. Functional dichotomy in spinal- vs prefrontal-projecting locus coeruleus modules splits descending noradrenergic analgesia from ascending aversion and anxiety in rats. eLife 2017;6:e29808.

[26] Ho Kim S, Mo Chung J. An experimental model for peripheral neuropathy produced by segmental spinal nerve ligation in the rat. PAIN 1992;50:355-63.

[27] Hughes S, Hickey L, Donaldson LF, Lumb BM, Pickering AE. Intrathecal reboxetine suppresses evoked and ongoing neuropathic pain behaviours by restoring spinal noradrenergic inhibitory tone. PAIN 2015;156:328-34.

[28] Hughes SW, Hickey L, Hulse RP, Lumb BM, Pickering AE. Endogenous analgesic action of the pontospinal noradrenergic system spatially restricts and temporally delays the progression of neuropathic pain following tibial nerve injury. PAIN 2013;154:1680-90.

[29] Jasmin L, Boudah A, Ohara PT. Long-term effects of decreased noradrenergic central nervous system innervation on pain behavior and opioid antinociception. J Comp Neurol 2003;460:38-55.
[30] Johansen JP, Fields HL, Manning BH. The affective component of pain in rodents: direct evidence for a contribution of the anterior cingulate cortex. Proc Natl Acad Sci U S A 2001;98:8077-82.

[31] Kawasaki Y, Kumamoto E, Furue H, Yoshimura M. $\alpha 2$ adrenoceptor-mediated presynaptic inhibition of primary afferent glutamatergic transmission in rat substantia gelatinosa neurons. Anesthesiology 2003;98:682-9.

[32] King T, Vera-Portocarrero L, Gutierrez T, Vanderah TW, Dussor G, Lai J, Fields HL, Porreca F. Unmasking the tonic-aversive state in neuropathic pain. Nat Neurosci 2009;12:1364-6.

[33] Lee J, Dougherty PM, Antezana D, Lenz FA. Responses of neurons in the region of human thalamic principal somatic sensory nucleus to mechanical and thermal stimuli graded into the painful range. J Comp Neurol 1999;410:541-55.

[34] Leith JL, Koutsikou S, Lumb BM, Apps R. Spinal processing of noxious and innocuous cold information: differential modulation by the periaqueductal gray. J Neurosci 2010;30:4933-42.

[35] Lenz FA, Garonzik IM, Zirh TA, Dougherty PM. Neuronal activity in the region of the thalamic principal sensory nucleus (ventralis caudalis) in patients with pain following amputations. Neuroscience 1998;86: 1065-81.

[36] Lenz FA, Kwan HC, Martin R, Tasker R, Richardson RT, Dostrovsky JO. Characteristics of somatotopic organization and spontaneous neuronal activity in the region of the thalamic principal sensory nucleus in patients with spinal cord transection. J Neurophysiol 1994;72:1570-87.

[37] Lenz FA, Seike M, Richardson RT, Lin YC, Baker FH, Khoja I, Jaeger CJ, Gracely $\mathrm{RH}$. Thermal and pain sensations evoked by microstimulation in the area of human ventrocaudal nucleus. J Neurophysiol 1993;70:200-12.

[38] Malmberg AB, Hedley LR, Jasper JR, Hunter JC, Basbaum Al. Contribution of alpha(2) receptor subtypes to nerve injury-induced pain and its regulation by dexmedetomidine. $\mathrm{Br} J$ Pharmacol 2001;132: 1827-36.

[39] Mansikka H, Lahdesmaki J, Scheinin M, Pertovaara A. Alpha(2A) adrenoceptors contribute to feedback inhibition of capsaicin-induced hyperalgesia. Anesthesiology 2004;101:185-90.

[40] Martin TJ, Kim SA, Eisenach JC. Clonidine maintains intrathecal selfadministration in rats following spinal nerve ligation. PAIN 2006;125: 257-63.

[41] Martin WJ, Gupta NK, Loo CM, Rohde DS, Basbaum Al. Differential effects of neurotoxic destruction of descending noradrenergic pathways on acute and persistent nociceptive processing. PAIN 1999;80:57-65.

[42] Marwaha J, Kehne JH, Commissaris RL, Lakoski J, Shaw W, Davis M. Spinal clonidine inhibits neural firing in locus coeruleus. Brain Res 1983; 276:379-83.

[43] Monconduit L, Lopez-Avila A, Molat JL, Chalus M, Villanueva L. Corticofugal output from the primary somatosensory cortex selectively modulates innocuous and noxious inputs in the rat spinothalamic system. J Neurosci 2006;26:8441-50.

[44] Niesters M, Proto PL, Aarts L, Sarton EY, Drewes AM, Dahan A. Tapentadol potentiates descending pain inhibition in chronic pain patients with diabetic polyneuropathy. Br J Anaesth 2014;113:148-56.

[45] O'Neill J, Sikandar S, McMahon SB, Dickenson AH. Human psychophysics and rodent spinal neurones exhibit peripheral and central mechanisms of inflammatory pain in the UVB and UVB heat rekindling models. J Physiol 2015;593:4029-42.

[46] Ohara S, Weiss N, Lenz FA. Microstimulation in the region of the human thalamic principal somatic sensory nucleus evokes sensations like those of mechanical stimulation and movement. J Neurophysiol 2004;91: 736-45.

[47] Olave MJ, Maxwell DJ. Neurokinin-1 projection cells in the rat dorsal horn receive synaptic contacts from axons that possess alpha2C-adrenergic receptors. J Neurosci 2003;23:6837-46.

[48] Palecek J, Paleckova V, Dougherty PM, Carlton SM, Willis WD. Responses of spinothalamic tract cells to mechanical and thermal stimulation of skin in rats with experimental peripheral neuropathy. J Neurophysiol 1992;67:1562-73.

[49] Pape HC, McCormick DA. Noradrenaline and serotonin selectively modulate thalamic burst firing by enhancing a hyperpolarizationactivated cation current. Nature 1989;340:715-18.

[50] Patel R, Dickenson AH. Neuronal hyperexcitability in the ventral posterior thalamus of neuropathic rats: modality selective effects of pregabalin. J Neurophysiol 2016;116:159-70.

[51] Patel R, Goncalves L, Leveridge M, Mack SR, Hendrick A, Brice NL, Dickenson AH. Anti-hyperalgesic effects of a novel TRPM8 agonist in neuropathic rats: a comparison with topical menthol. PAIN 2014;155: 2097-107.

[52] Pinault D. The thalamic reticular nucleus: structure, function and concept. Brain Res Brain Res Rev 2004;46:1-31. 
[53] Qu C, King T, Okun A, Lai J, Fields HL, Porreca F. Lesion of the rostral anterior cingulate cortex eliminates the aversiveness of spontaneous neuropathic pain following partial or complete axotomy. PAIN 2011;152: 1641-8.

[54] Rahman W, D'Mello R, Dickenson AH. Peripheral nerve injury-induced changes in spinal alpha(2)-adrenoceptor-mediated modulation of mechanically evoked dorsal horn neuronal responses. J Pain 2008;9: 350-9.

[55] Rahman W, Suzuki R, Hunt SP, Dickenson AH. Selective ablation of dorsal horn NK1 expressing cells reveals a modulation of spinal alpha2adrenergic inhibition of dorsal horn neurones. Neuropharmacology 2008; 54:1208-14.

[56] Rainville P, Duncan GH, Price DD, Carrier B, Bushnell MC. Pain affect encoded in human anterior cingulate but not somatosensory cortex. Science 1997;277:968-71.

[57] Rinaldi PC, Young RF, Albe-Fessard D, Chodakiewitz J. Spontaneous neuronal hyperactivity in the medial and intralaminar thalamic nuclei of patients with deafferentation pain. J Neurosurg 1991;74:415-21.

[58] Roeder Z, Chen Q, Davis S, Carlson JD, Tupone D, Heinricher MM. Parabrachial complex links pain transmission to descending pain modulation. PAIN 2016;157:2697-708.

[59] Sagen J, Proudfit HK. Effect of intrathecally administered noradrenergic antagonists on nociception in the rat. Brain Res 1984;310:295-301.

[60] Simpson DM, Schifitto G, Clifford DB, Murphy TK, Durso-De Cruz E, Glue P, Whalen E, Emir B, Scott GN, Freeman R. Pregabalin for painful HIV neuropathy: a randomized, double-blind, placebo-controlled trial. Neurology 2010;74:413-20.

[61] Sonohata M, Furue H, Katafuchi T, Yasaka T, Doi A, Kumamoto E, Yoshimura M. Actions of noradrenaline on substantia gelatinosa neurones in the rat spinal cord revealed by in vivo patch recording. J Physiol 2004;555(pt 2):515-26.

[62] Stone LS, Broberger C, Vulchanova L, Wilcox GL, Hokfelt T, Riedl MS, Elde R. Differential distribution of alpha2A and alpha2C adrenergic receptor immunoreactivity in the rat spinal cord. J Neurosci 1998;18: 5928-37.

[63] Stone LS, Vulchanova L, Riedl MS, Wang J, Williams FG, Wilcox GL, Elde $\mathrm{R}$. Effects of peripheral nerve injury on alpha-2A and alpha-2C adrenergic receptor immunoreactivity in the rat spinal cord. Neuroscience 1999;93: 1399-407.

[64] Sullivan AF, Dashwood MR, Dickenson AH. $\alpha 2$-Adrenoceptor modulation of nociception in rat spinal cord: location, effects and interactions with morphine. Eur J Pharmacol 1987;138:169-77.

[65] Suzuki R, Dickenson AH. Differential pharmacological modulation of the spontaneous stimulus-independent activity in the rat spinal cord following peripheral nerve injury. Exp Neurol 2006;198:72-80.

[66] Suzuki R, Green GM, Millan MJ, Dickenson AH. Electrophysiologic characterization of the antinociceptive actions of S18616, a novel and potent alpha 2-adrenoceptor agonist, after acute and persistent pain states. J Pain 2002;3:234-43.
[67] Suzuki R, Morcuende S, Webber M, Hunt SP, Dickenson AH. Superficial NK1-expressing neurons control spinal excitability through activation of descending pathways. Nat Neurosci 2002;5:1319-26.

[68] Vaegter HB, Graven-Nielsen T. Pain modulatory phenotypes differentiate subgroups with different clinical and experimental pain sensitivity. PAIN 2016;157:1480-8.

[69] Vos BP, Benoist JM, Gautron M, Guilbaud G. Changes in neuronal activities in the two ventral posterior medial thalamic nuclei in an experimental model of trigeminal pain in the rat by constriction of one infraorbital nerve. Somatosens Mot Res 2000;17:109-22.

[70] Watson C, Paxinos G. The rat brain in stereotaxic coordinates. 6th ed: Elsevier Academic Press, 2006.

[71] Wei H, Pertovaara A. Spinal and pontine alpha2-adrenoceptors have opposite effects on pain-related behavior in the neuropathic rat. Eur $J$ Pharmacol 2006;551:41-9.

[72] Weng HR, Lee JI, Lenz FA, Schwartz A, Vierck C, Rowland L, Dougherty PM. Functional plasticity in primate somatosensory thalamus following chronic lesion of the ventral lateral spinal cord. Neuroscience 2000;101: 393-401.

[73] Xie JY, Herman DS, Stiller CO, Gardell LR, Ossipov MH, Lai J, Porreca F, Vanderah TW. Cholecystokinin in the rostral ventromedial medulla mediates opioid-induced hyperalgesia and antinociceptive tolerance. J Neurosci 2005;25:409-16.

[74] Xie JY, Qu C, Patwardhan A, Ossipov MH, Navratilova E, Becerra L, Borsook D, Porreca F. Activation of mesocorticolimbic reward circuits for assessment of relief of ongoing pain: a potential biomarker of efficacy. PAIN 2014;155:1659-66.

[75] Xu M, Kontinen VK, Kalso E. Endogenous noradrenergic tone controls symptoms of allodynia in the spinal nerve ligation model of neuropathic pain. Eur J Pharmacol 1999;366:41-5.

[76] Xu XJ, Puke MJ, Wiesenfeld-Hallin Z. The depressive effect of intrathecal clonidine on the spinal flexor reflex is enhanced after sciatic nerve section in rats. PAIN 1992;51:145-51.

[77] Yaksh TL, Rudy TA. Chronic catheterization of the spinal subarachnoid space. Physiol Behav 1976;17:1031-6.

[78] Yarnitsky D, Crispel Y, Eisenberg E, Granovsky Y, Ben-Nun A, Sprecher E, Best LA, Granot M. Prediction of chronic post-operative pain: preoperative DNIC testing identifies patients at risk. PAIN 2008;138:22-8.

[79] Yarnitsky D, Granot M, Nahman-Averbuch H, Khamaisi M, Granovsky Y. Conditioned pain modulation predicts duloxetine efficacy in painful diabetic neuropathy. PAIN 2012;153:1193-8.

[80] Yokota T, Asato F, Koyama N, Masuda T, Taguchi H. Nociceptive body representation in nucleus ventralis posterolateralis of cat thalamus. J Neurophysiol 1988;60:1714-27.

[81] Zhang C, Guo YQ, Qiao JT, Dafny N. Locus coeruleus modulates thalamic nociceptive responses via adrenoceptors. Brain Res 1998;784: 116-22.

[82] Zimmermann M. Ethical guidelines for investigations of experimental pain in conscious animals. PAIN 1983;16:109-10. 